\title{
Atomic and Close-to-Atomic Scale Manufacturing: A Review on Atomic Layer Removal Methods Using Atomic Force Microscopy
}

\author{
Paven Thomas Mathew ${ }^{1} \cdot$ Brian J. Rodriguez ${ }^{2,3} \cdot$ Fengzhou Fang $^{1,4}$
}

Received: 21 April 2020 / Revised: 30 May 2020 / Accepted: 5 June 2020 / Published online: 26 June 2020

(c) The Author(s) 2020

\begin{abstract}
Manufacturing at the atomic scale is the next generation of the industrial revolution. Atomic and close-to-atomic scale manufacturing (ACSM) helps to achieve this. Atomic force microscopy (AFM) is a promising method for this purpose since an instrument to machine at this small scale has not yet been developed. As the need for increasing the number of electronic components inside an integrated circuit chip is emerging in the present-day scenario, methods should be adopted to reduce the size of connections inside the chip. This can be achieved using molecules. However, connecting molecules with the electrodes and then to the external world is challenging. Foundations must be laid to make this possible for the future. Atomic layer removal, down to one atom, can be employed for this purpose. Presently, theoretical works are being performed extensively to study the interactions happening at the molecule-electrode junction, and how electronic transport is affected by the functionality and robustness of the system. These theoretical studies can be verified experimentally only if nano electrodes are fabricated. Silicon is widely used in the semiconductor industry to fabricate electronic components. Likewise, carbon-based materials such as highly oriented pyrolytic graphite, gold, and silicon carbide find applications in the electronic device manufacturing sector. Hence, ACSM of these materials should be developed intensively. This paper presents a review on the state-of-the-art research performed on material removal at the atomic scale by electrochemical and mechanical methods of the mentioned materials using AFM and provides a roadmap to achieve effective mass production of these devices.
\end{abstract}

Keywords Atomic force microscopy $\cdot$ Atomic-scale manufacturing $\cdot$ Molecular scale devices $\cdot$ Electrochemistry $\cdot$ ACSM . Manufacturing III

\section{Introduction}

The world has improved in all forms from the ancient stone age from around 2 million years ago to the present postmodernity age. Among them, manufacturing technology was a milestone for all civilizations. It has formed the backbone

Fengzhou Fang

fengzhou.fang@ucd.ie

1 Centre of Micro/Nano Manufacturing Technology (MNMT-Dublin), University College Dublin, Dublin D04V1W8, Ireland

2 School of Physics, University College Dublin, Belfield, Dublin D04V1W8, Ireland

3 Conway Institute of Biomolecular and Biomedical Research, University College Dublin, Belfield, Dublin D04V1W8, Ireland

4 State Key Laboratory of Precision Measuring Technology and Instruments, Centre of Micro/Nano Manufacturing Technology, MNMT, Tianjin University, Tianjin 300072, China of a country's wealth and power. The industrial sector has emerged from steam engines to programmable logic controllers (PLC) [1]. The reason for these developments is the need for ultimate technological outgrowth.

The best example of this is the increasing number of transistors on an integrated circuit (IC) chip. The first transistor was developed in 1947 at Bell Laboratories, where they used a single transistor for the study [2]. There are around 19.2 billion or more transistors on a present-day chip. This is in favor of the famous Moore's law, according to which the number of transistors doubles every 24 months [3], even though the doubling is happening every 18 months in the 
present-day scenario [4]. In order to accommodate more transistors on a chip, their size should be reduced even further.

Atomic force microscopy (AFM) is an astounding and promising tool for the reduction of material size to the nanometer scale and extensive research has been performed since its discovery in 1986 by Binning and coworkers [5]. If pushed further, its abilities can be drawn towards manufacturing at the atomic scale. The applications of AFM in manufacturing include scratching [6-13], patterning the structures [14-17], and biomedical applications [18-20].

Apart from that, AFM has great potential to deal with the first characteristic of atomic and close-to-atomic-scale manufacturing (ACSM), since individual atoms can be manipulated and displaced using AFM, as shown by Morita et al. [21], where they positioned atoms using non-contact AFM (NC-AFM). In addition, other scanning probe microscopes (SPM) such as scanning tunneling microscope (STM) have the ability to move single atoms, which was explored by IBM Research in making the world's smallest motion film named, 'A Boy and His Atom', by moving single atoms frame by frame.

Conducting probe atomic force microscopy (c-AFM) is found to have a novel application in the patterning of single atoms [22], over semiconducting and metallic surfaces $[23,24]$. Also, c-AFM has been employed in nanopatterning research over highly oriented pyrolytic graphite (HOPG) [25], graphene oxide [26], and other carbon-based materials such as carbon nanotubes (CNT) [27] and graphene flakes [28-30]. Also, recent works performed by Buckwell et al. [31] and Steffes et al. [32] have emphasized the importance of conductance tomographic AFM (T-AFM). A wide range of research has been carried out using AFM in material removal research $[33,34]$. Very recently, Rashidi and Wolkow [35] have developed an automation method using artificial intelligence for automated atomic-scale manufacturing.

These material removal applications of AFM make it a leading candidate for the future development of ACSM [36]. Attaining single atomic layer removal is the goal that every researcher in this field is aiming at, even though much progress is needed to achieve this reliably. Different methods and perspectives are being approached by the researchers, such as mechanical [34, 37, 38], mechanochemical [6, 39, 40], and electrochemical [41, 42], to perfectly remove an atomic layer from a substrate.

When it comes to manufacturing, mechanical methods are the most basic approach towards material removal. This can be precisely performed at the micrometer scale, beyond that, it is a daunting task. To overcome this problem, basic knowledge of the mechanism of nanomanufacturing should be extended in a different aspect [43]. These include approaches such as scratching, and piercing by AFM, but the major issue lies in the material removal mechanism. We require chip formation as the dominant mechanism rather than plastic deformation. AFM-based mechanical machining has the disadvantage of ridge formation or the accumulation of materials around the features [44].

This issue was solved by the research of Gozen and Ozdoganlar [37] in which they used AFM tip as a drilling machine and named the process "nanomilling." In their research, the AFM tip was rotated at high frequency with the help of a three-axis piezoelectric actuator, while keeping the sample stationary. As a result, they were able to produce long curly chips as the product of material removal and thereby established the dominance of shear mechanism using rotary motion of an AFM tip. Similar work performed recently by Geng et al. [45] also showed the formation of chips with the nanomilling process. In their study, they performed the experiments in two cycles: the first half formed the outer profile and the second half formed the inner profile. They used a poly(methyl)methacrylate (PMMA) substrate and a silicon tip and established the importance of nanomilling in nanofluidic applications. In comparison with these milling processes, the residual materials formed affect the surface quality of microchannels, which can be improved by optimizing parameters such as cutting depth, feeding rate, and tool-path strategy [46].

However, when chemical methods are mixed with mechanical processes, precision can be extended to the atomic scale because the mechanical energy can be used to activate chemical reactions [38]. A recent study performed by Chen et al. [6] revealed that a single atomic layer of $\mathrm{Si}$ can be removed via a mechanochemical method, which was theoretically verified using molecular dynamics simulations. They performed experiments in a humid environment with relative humidity (RH) of $75 \% \pm 2 \%$ using a silica sphere of radius $1.25 \mu \mathrm{m}$ as the AFM tip for the material removal process. In their observation, the mechanical pressure applied determined the number of layers to be removed and an upper bound of $247 \mathrm{MPa}$ was set out, below which no removal was obtained. Apart from that, a chemically reactive counter surface, i.e., the probe, was required for the atomic layer removal, whereby water adsorption along with the counter surface enhanced the removal mechanism at the atomic scale.

Electrochemical AFM material removal methods are currently the trending and promising approaches for nano/ atomic-scale manufacturing. This includes the oxidation reaction happening at the junction between the AFM tip and the substrate, known as the local anodic oxidation (LAO). Different substrates are used such as graphene [47], silicon (Si) $[48,49]$, highly oriented pyrolytic graphite (HOPG) [50], and other materials such as polymers [51-53], glass 
[54], and mica [55]. Even though much progress has been made in this field, more work remains to be conducted.

Detailed reviews on mechanical material removal using AFM [56], mechanochemical nanofabrication processes on Si [38], micro/nano-cutting [57] and tip-based nanomachining [58] are published. Also, a comprehensive explanation of different material categories for AFM based and other tip-based machining can be referred from [55]. Hence, we provide a short review on different state-of-the art AFM material removal studies, focusing mainly on electrochemical methods, and some novel mechanical removal research, conducted on $\mathrm{Si}, \mathrm{HOPG}$, gold $(\mathrm{Au})$, and silicon carbide $(\mathrm{SiC})$, over the last two decades. The summarized properties of these materials are given in Table 1.

The mechanism of electrochemical AFM etching is fairly simple. Electrochemical reactions can take place when there are applied voltage, electrodes, and electrolyte. The AFM tip and the substrate act as two electrodes (electrode 1 and electrode 2), and the water meniscus formed at the tip-substrate junction acts as the electrolyte [67], as shown in Fig. 1. These electrodes can be made anode or cathode depending on the connection given. This method can help in selectively modifying the surface chemistry with nanometer scale resolution [68-70].

The electric field dissociates the water molecules into negatively charged hydroxides, as shown in Eq. (1), and these react with the material atoms [71].

$2 \mathrm{H}_{2} \mathrm{O}+2 \mathrm{e}^{-} \rightarrow \mathrm{H}_{2}+2 \mathrm{OH}^{-}$

The mechanism of electrochemical etching varies with the materials used. The Si surface oxidation by AFM is widely studied [72-75]. Here, the $\mathrm{OH}^{-}$ions react with $\mathrm{Si}$ to form silicon dioxide $\left(\mathrm{SiO}_{2}\right)$ as in Eq. (2) [76].

$\mathrm{Si}+2 \mathrm{OH}^{-} \rightarrow \mathrm{SiO}_{2}+2 \mathrm{H}^{+}+4 \mathrm{e}^{-}$

These dioxides are accumulated over the substrate, extending underneath it, forming the convex structures, which can be removed by etching with acidic solutions to achieve concave features, leading to material removal.

In the case of HOPG, the water is adsorbed over the graphite under wet conditions, above $15 \% \mathrm{RH}[50,77]$. The $\mathrm{O}^{-}$and $\mathrm{OH}^{-}$ions can interact with the carbon on the HOPG surface and form carbon monoxide (CO) and carbon

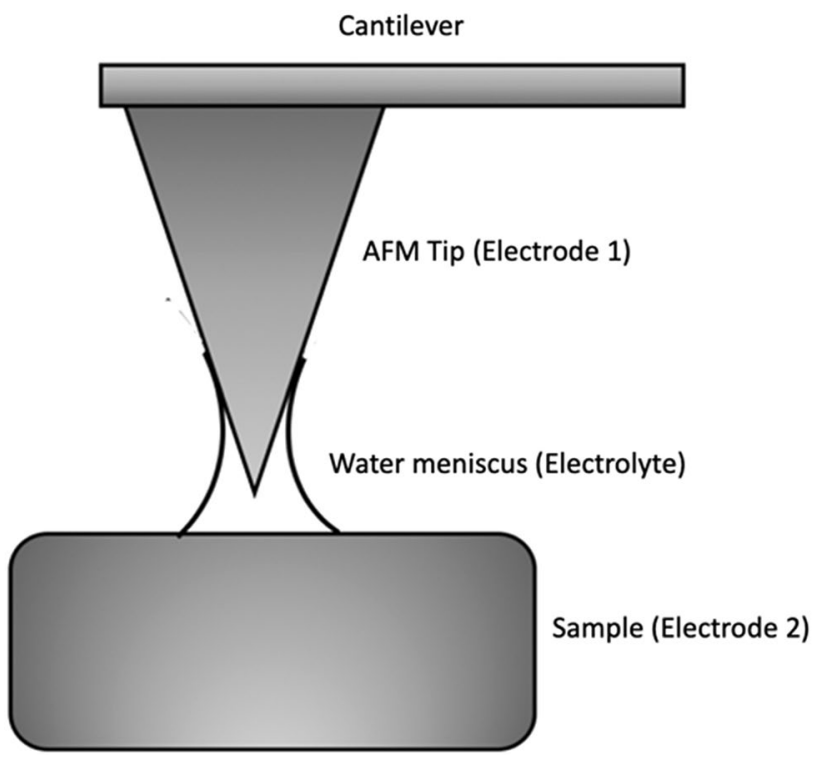

Fig. 1 The electrochemical cell formation with an AFM tip and sample

dioxide $\left(\mathrm{CO}_{2}\right)$, as given by Eqs. (3) and (4). These gases get removed from the surface and result in the material removal mechanism.

$\mathrm{C}+\mathrm{O}_{2} \rightarrow \mathrm{CO}_{2}$

$\mathrm{C}+\mathrm{H}_{2} \mathrm{O} \rightarrow \mathrm{CO}+\mathrm{H}_{2}$

In the case of $\mathrm{SiC}$, the oxidation takes place by the following, as given in Eqs. (5) and (6) [78].

$\mathrm{SiC}+2 \mathrm{H}_{2} \mathrm{O}+4 \mathrm{~h}^{+} \rightarrow \mathrm{SiO}_{2}+4 \mathrm{H}^{+}+\mathrm{C}^{4+}$

$\mathrm{SiC}+3 / 2 \mathrm{O}_{2}+4 \mathrm{~h}^{+} \rightarrow \mathrm{SiO}_{2}+\mathrm{CO}$

A direct anodic reaction over $\mathrm{SiC}$ [79] can be given by,

$\mathrm{SiC}+8 \mathrm{~h}^{+}+4 \mathrm{OH}^{-} \rightarrow \mathrm{SiO}_{2}+4 \mathrm{H}^{+}+\mathrm{CO}_{2}$

However, formation of an oxide over $\mathrm{SiC}$ is more difficult than over $\mathrm{Si}$, since the $\mathrm{Si}-\mathrm{C}$ bond is stronger than the $\mathrm{Si}-\mathrm{Si}$ bond [78]. Apart from that, much higher energy is required for the removal of carbon in the form of $\mathrm{CO}$.
Table 1 Material properties of $\mathrm{Si}, \mathrm{HOPG}, \mathrm{Au}$, and $\mathrm{SiC}$

\begin{tabular}{lllll}
\hline Material & Density (gm/cc) [59] & Hardness (Mohs) [59] & Tensile strength (MPa) & $\begin{array}{l}\text { Fracture tough- } \\
\text { ness }\left(\mathrm{MPa} \mathrm{m}^{1 / 2}\right)\end{array}$ \\
\hline $\mathrm{Si}$ & 2.33 & 6.5 & $1180[59]$ & $1[60]$ \\
$\mathrm{HOPG}$ (graphite) & 2.25 & 0.5 & $3.43-17.2[59]$ & $2.25[61]$ \\
$\mathrm{Au}$ & $19.3[62]$ & $2.5-3[63]$ & $137[59]$ & $2[64]$ \\
$\mathrm{SiC}[65]$ & 3.1 & $9-10[63]$ & $1625[66]$ & 4.6 \\
\hline
\end{tabular}


The different studies on the four substrates are given in Sect. 2. Detailed information on the research trends in this field and the future outlooks are depicted in Sect. 3 and finally, concluding remarks are given in Sect. 4.

\section{Electrochemical and Mechanical Material Removal Using AFM}

\subsection{Silicon: The Most Widely Used Semiconductor Material in the Electronics Industry}

Single-crystal silicon is well known for its electrical as well as mechanical properties [80]. Si is found to have native oxides over them, which aids in the formation of oxide deposits [81]. This oxide deposit can be removed by treating the sample with hydrofluoric (HF) solution. Many attempts have been made in the late 90 s to pattern oxide structures as the application for developing nanoscale electronic devices [82-85]. These experiments are further extended to attain atomic layer removal for the application of fabricating nanoelectrodes, which are essential for developing molecular electronic devices such as transistors and switches [39, 40, $48,86,87]$. Also, nanometric cutting over monocrystalline silicon under high vacuum conditions in a scanning electron microscope (SEM) has also been developed to study the nanoscale material removal behavior [88].

Different factors such as sample material, tip speed, applied force, applied voltage, tip angle, sliding direction, humidity, and sample orientation, affect the material removal mechanism. In most of the research performed, n-type/ptype silicon in its (100) orientation is used as the substrate. A possible reason could be that the silicon etching in alkaline solutions stops at the (111) orientation [80, 89, 90]. Also, the $\mathrm{Si} / \mathrm{SiO}_{2}$ state density is lower for (100) than the (110), (111), and other orientations, and, as a result, lower amounts of dangling bonds are present, yielding higher carrier mobility. Apart from that, negative bias is given to the tip to make it anode and enable anodic oxidation. It is claimed that oxidation happens only when the tip is grounded, and sample is given positive voltage [76]. In addition, factors such as electric field strength, surface stress, water meniscus formation, and $\mathrm{OH}^{-}$diffusion are responsible for the mechanism and kinetics of oxide formation [72, 73, 91, 92].

Tip material is an important factor in atomic-scale machining. Various tips such as pyramidal silicon nitride $\left(\mathrm{Si}_{3} \mathrm{~N}_{4}\right)$ [82, 83, 85], diamond [40], diamond-like carbon (DLC) coated [86], NSC21/Ti-Pt probe [76], NSC18/Ti-Pt probe [93], and so on are used for the experimentation over Si. A detailed review on diamond machining over Si based on molecular simulations can be referred from [94]. It has been noted that the nanoscale tip wear is a major problem faced by researchers while machining atomic structures over the substrates. Wear occurring on $\mathrm{Si}_{3} \mathrm{~N}_{4}$ tips while scanning in contact mode under applied loads of 20-100 $\mathrm{nN}$ is reported in earlier studies $[95,96]$. Experiments performed by Fletcher et al. [97] have shown the durability of ultranano-crystalline diamond (UNCD) tips scanned over different substrates such as quartz, $\mathrm{SiC}, \mathrm{Si}$, or UNCD. They applied forces up to $200 \mathrm{nN}$ and temperatures up to $400{ }^{\circ} \mathrm{C}$. Si tips were found to experience severe damage over quartz and UNCD, while moderate damage occurred over $\mathrm{Si}$ and $\mathrm{SiC}$ (except for temperature at $400{ }^{\circ} \mathrm{C}$, where the damage was extreme). On the other hand, UNCD tips were unaffected over Si. These tip degradations and wear can be identified and quantified to improve the experimental results [98]. Coating a silicon tip can reduce the wear such as $\mathrm{SiO}_{2}$ tip encapsulation [99], platinum silicide [100], and diamond particles [101-103]. Another way of reducing wear using molding technique has also been reported to fabricate monolithic ultra-sharp tips of DLC with Si (Si-DLC) [104]. Single-crystal diamond probes are well suited and are commercially available for machining purposes. However, the main concern is to achieve direct etching over $\mathrm{Si}$ at the atomic scale, with cost-effective methods. DLC-coated probes could be used for this purpose. It is found to have less wear resistance due to its high hardness, elastic modulus, low wear, and tribological properties [105].

A way of achieving direct etching on Si substrate was investigated by Yamamoto et al. [48]. They used a catalytically active platinum-coated AFM probe instead of DLC-coated probes. The experimental setup consisted of a three-electrode system, with $\mathrm{Ag} / \mathrm{AgCl}$ as the reference electrode (RE), rather than a two-electrode system. They etched using three different probes: uncoated Si, Pt-coated, and Au-coated. Protuberances of height ranging between 2 and $5 \mathrm{~nm}$ with uncoated $\mathrm{Si}$, narrow grooves of $\sim 0.8 \mathrm{~nm}$ and a width of $\sim 170 \mathrm{~nm}$ with Pt-coated, and shallow grooves less than $0.1 \mathrm{~nm}$ with $\mathrm{Au}$-coated probes were obtained, as shown in Fig. 2.

Jiang et al. [86] achieved direct etching over p-type Si (100) using DLC coated Si probe. First, they scratched two lines on the surface, both being parallel but scratched in opposite directions, forward and backward, with a normal force of $10 \mu \mathrm{N}$ and a tip speed of $1 \mu \mathrm{m} / \mathrm{s}$. A deeper groove was achieved for the forward when compared to the backward direction, as shown in Fig. 3a, b. This can be due to the tip damage or the bending of cantilever corresponding to the direction of scratching [92]. Apart from that, they have investigated the effects of applied tip force, scratch speed, scratch direction, and number of scratches on the geometry of already-scratched surfaces. In their experiments, they have reported an increase of depth from 0.68 to $3.35 \mathrm{~nm}$ and a width from 21.59 to $26.19 \mathrm{~nm}$ corresponding to an increase of applied force from 1 to $20 \mu \mathrm{N}$ as shown in Fig. 3c, d, which is graphically shown in Fig. $3 \mathrm{e}$. 
(a)
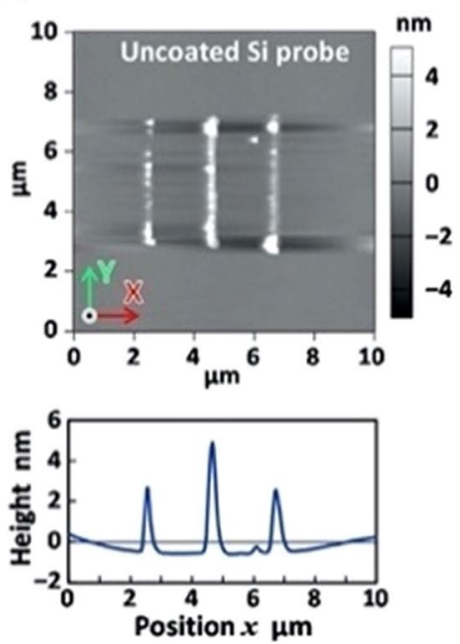

(b)

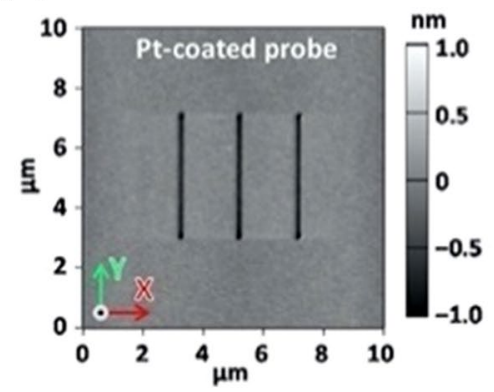

(c)
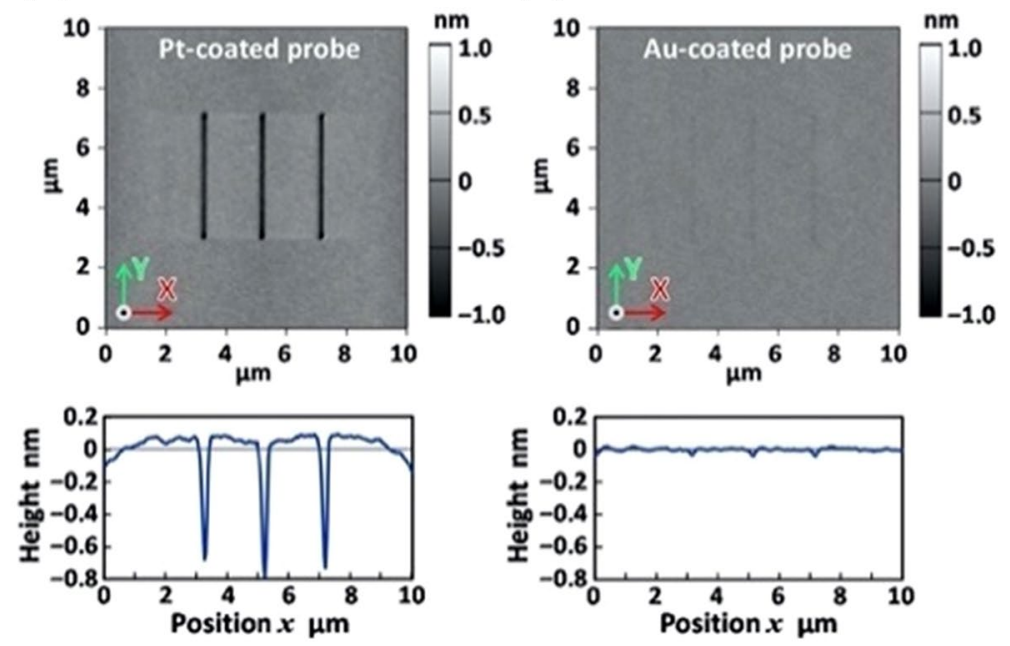

Fig. 2 Etching on a silicon substrate with a uncoated Si probe, $\mathbf{b}$ with Pt-coated probe, and $\mathbf{c}$ with Au-coated probe. Figures below show the cross-sectional profiles of the grooves. Reproduced from Ref. [48]. Copyright Elsevier

On the other hand, depth decreased slightly from 3.09 to $2.73 \mathrm{~nm}$ when the tip speed was increased from 0.1 to $10 \mu \mathrm{m} / \mathrm{s}$, as shown in Fig. 3f, g. The depth and width increased linearly when scratched repeatedly with some debris deposited along the bank of grooves. All calculations were performed in ambient air. Hence, DLC-coated probes with optimum parameters could be a successful cost-effective candidate for achieving atomic-scale material removal, even though they exhibit lower resolution than single-crystal diamond.

The application of AFM machining over Si in fabricating nanofluidic devices by scratching the surface by the principle of electrochemical etching has been conducted by Promyoo et al. [106]. They also reported the importance of machining parameters such as scratching speed, feed rate, scratching direction, applied load, tip geometry, tip angle, tip radius, and number of scratching cycles in the formation of chip, surface roughness, and machines geometry. They were able to create increased depths with the applied force. Parameters such as $243.75 \mu \mathrm{N}$ scratching force, tip surface approaching speed of $1 \mathrm{~Hz}$, scratch rate of $0.996 \mathrm{~Hz}$, and step over $10 \mathrm{~nm}$ were found to be optimum for scratching the surface. Nanochannel depths of $\sim 30 \mathrm{~nm}$ were obtained.

These types of experiments [107] find their application in developing molecular devices such as transistors, by incorporating molecules through the nanochannels and bonding with the nanoelectrodes fabricated through the AFM machining. Theoretical studies could aid for the selection of molecules and substrates to study the bonding interactions between them [108].

Another important factor that affects the electrochemical etching process over $\mathrm{Si}$ is the presence of humidity.
Experiments have been performed both in humid environment [40, 83, 84] and in ambient air [76, 105]. Typically, in most of the research with an external setup to provide a humid environment, the $\mathrm{RH}$ is always in the range of $\sim 30 \%-90 \%$. This humid environment acts as an aid for the formation of oxide deposits over the Si substrate. Huang et al. [109] compared the effect of oxide heights in deionized (DI) water and in ambient air. They found an increased oxide height of $117.29 \mathrm{~nm}$ and a width of $551.28 \mathrm{~nm}$ in atmospheric conditions when compared with that performed in DI water, which was $66.6 \mathrm{~nm}$ high and $467.03 \mathrm{~nm}$ wide. The oxides formed can be treated with acidic solutions to attain concave features, leading to material removal.

Therefore, apart from the direct etching techniques over $\mathrm{Si}$, the oxidized substrate patterns can be treated with specific solutions such as $\mathrm{KOH}, \mathrm{HF}$, and $\mathrm{H}_{2} \mathrm{SO}_{4}$ to enable etching. The most widely used is diluted HF solution. $\mathrm{KOH}$ solutions can also be used but for removing the untreated silicon substrate rather than the oxide deposits formed. This $\mathrm{KOH}$ solution can be mixed with isopropyl alcohol (IPA) for smoothening the Si surface but the etching rate is reduced [110]. However, the etching rate is found to increase when IPA is mixed with highly concentrated $\mathrm{KOH}$, by controlling the temperature.

Some of the earlier works based on oxide formation are mentioned in the introduction of this review. Other than removal of oxides, material removal is possible with reduced tip wear, when a deposition is made over Si substrate. An example of this is the recent study performed by Geng et al. [111]. They deposited PMMA over the substrate before the scratching experiment. They combined this study with reactive ion etching (RIE) to produce grooves and holes on the 
Fig. 3 Direct etching over $\mathrm{Si}$ (100) with DLC-coated Si Probe. a The forward and backward direction of scratching. b The corresponding line profiles showing the depth of each lines. c-d Grooves with increased tip force. e Graph showing grooves as a function of applied force. $\mathbf{f}$ Grooves with increased tip speed and $\mathbf{g}$ relation of scratched grooves with scratch speed. Reproduced from Ref. [86]. Copyright Springer Publishing. CC BY 2.0 (a)

(b)

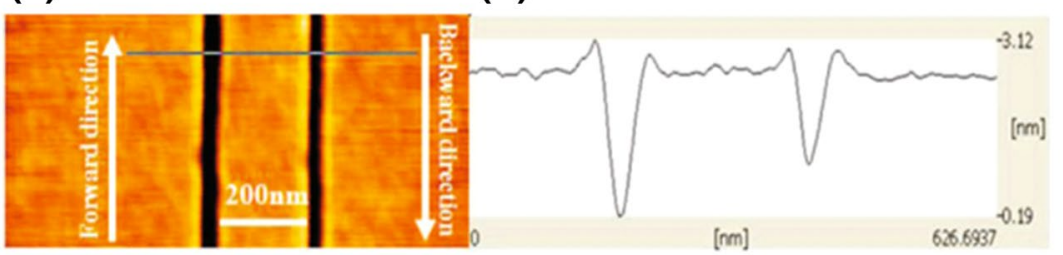

(c)

(d)
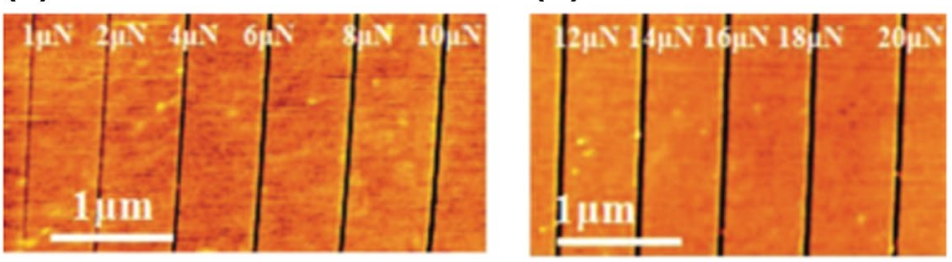

(e)

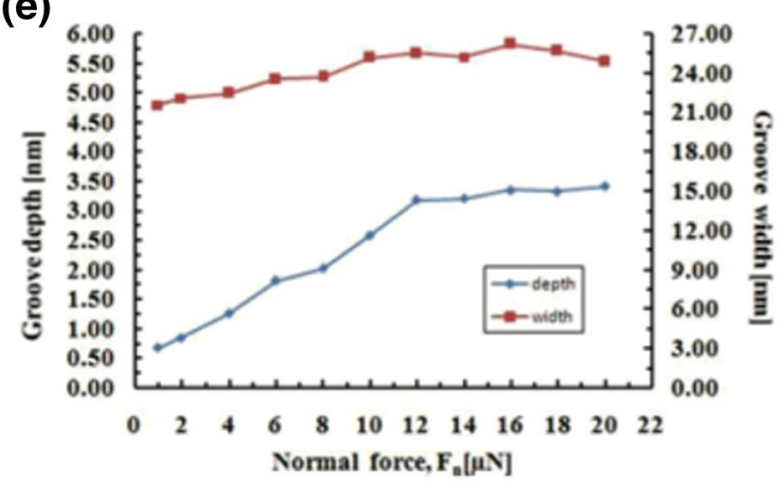

(g)

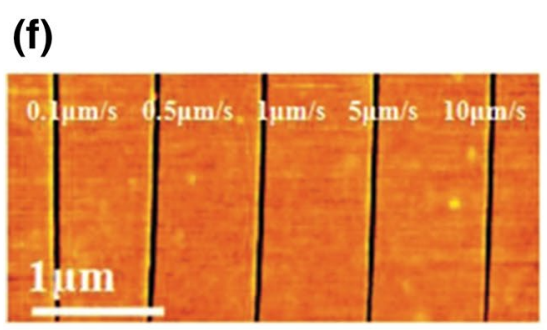

substrate. PMMA and aluminum thin films were used as the resist for the RIE process. This study enabled the possibilities to control the width of etched grooves with minimal tip damage.

Applying optimum force along with the reaction can successfully remove materials from the substrate. The main advantage of AFM is to provide nano and micro Newtons of force with precision, thereby controlling the depth of machining. Diamond probes $[112,113]$ are the most favored for this purpose, since they are hard and experience less wear while scratching over the substrate. This application of controlled force helps in attaining nanochannels over hard materials such as $\mathrm{Si}$ [112]. Work performed by Temiryazev [113] showed the importance of pulse force nanolithography using a sharp diamond probe to attain high aspect ratio grooves over Si substrate with 30-100 nm pitch and 5-52 nm depth.

Non-contact mode of electrochemical material removal is an effective approach to produce oxide structures over $\mathrm{Si}$, which can be subsequently removed by chemical etching [114]. One of the methods to achieve this mode of machining is through pulse electrochemical nanomachining (PECM) [115]. Pulse electrochemical polishing (PECP) of stainless steel and pulse electrochemical nanopatterning (PECN) over Si have been reported by Lee et al. [116] in 2013. However, very recently, a dedicated study on PECN as a possibility of nanofabrication in non-contact mode was conducted by Kim et al. [93]. The sample used was p-type $\mathrm{Si}(100)$ and the electrical conditions were fixed at $8 \mathrm{~V}$ and 
$5 \mathrm{kHz}$ at each position. They were able to produce nanoscale oxides in the non-contact mode, keeping a tip-sample distance of $0.1 \mu \mathrm{m}$ and $0.2 \mu \mathrm{m}$. They achieved oxide deposits by supplying ultrashort voltage pulses over specific positions with durations of 2, 50,100, and $190 \mu \mathrm{s}$, for $3 \mathrm{~min}$. When the tip-sample distance was $0.1 \mu \mathrm{m}$, the formed oxide height ranged from 0.34 to $1.6 \mathrm{~nm}$ and the width from 170 to $201 \mathrm{~nm}$ corresponding to the increase of pulse duration from 2 to $190 \mu \mathrm{s}$. On the other hand, for the tip-sample distance of $0.2 \mu \mathrm{m}$, the oxide height ranged from 0.65 to $5.40 \mathrm{~nm}$ and width from 100 to $187 \mathrm{~nm}$, for the mentioned pulse durations, as shown in Fig. 4. From this, it is clear that the overall dimension of the oxide increases as the distance of the tip from the sample increases. This is due to the water bridge formed at the tip-sample junction. When the substrate was treated with $25 \%$ aqueous HF solution for $20 \mathrm{~min}$, they achieved concave structures as small as $0.3 \mathrm{~nm}$, as shown in Fig. 5. The effect of tip-substrate distance on etching process of III-V semiconductors can be referred from [117]. Hence, according to their study, PECN could be considered as a novel method to achieve atomic-scale material removal and since this can be performed in non-contact mode, the tip wear can be reduced considerably.

Recently, Ki et al. [118] performed electrochemical local etching (ELE) to attain etching over Si using non-contact mode of AFM machining. They used polygon tips to etch through doped n-type Si substrate with the use of KOH. They were able to produce polygonal sub-micrometer
Fig. 4 Formation of nano oxide. a The nanoscale oxides formed with a tip-sample distance of $0.1 \mu \mathrm{m}$ and $\mathbf{b}$ its $3 \mathrm{D}$ topographical image. c The nanoscale oxides formed with a tip-sample distance of $0.2 \mu \mathrm{m}$ and $\mathbf{d}$ its 3D topographical image. Reproduced from Ref. [93]. Copyright IOP Publishing (a)

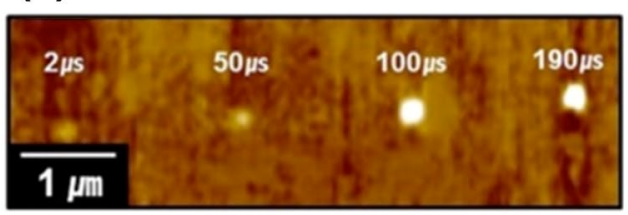

(c)

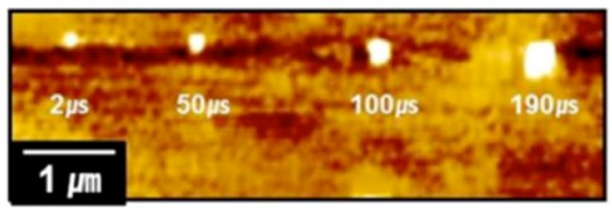

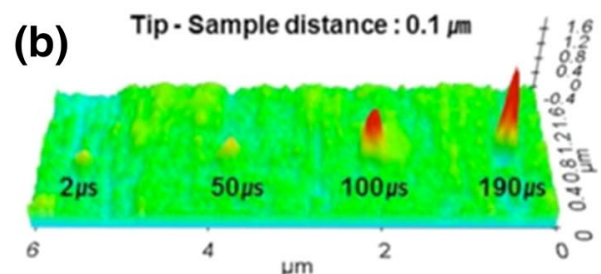

(d) Tip-Sample distance : $0.2 \mu \mathrm{m} \quad \begin{array}{r}\mathrm{nm} \\ 5 \\ 4\end{array}$

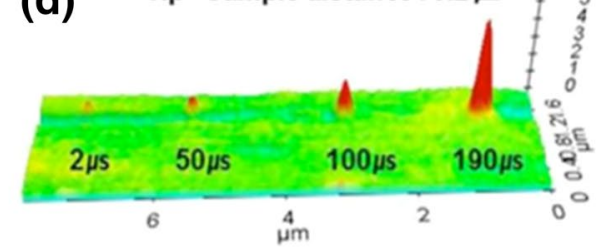

Fig. 5 The nanodot formation. a The nanodots formed after treating the substrate with $\mathrm{HF}$ solution. b-d The magnified and line profiles of nanodots for the time durations 190, 100, 50, and $2 \mu \mathrm{s}$, respectively (from left to right). Reproduced from Ref. [93]. Copyright IOP Publishing

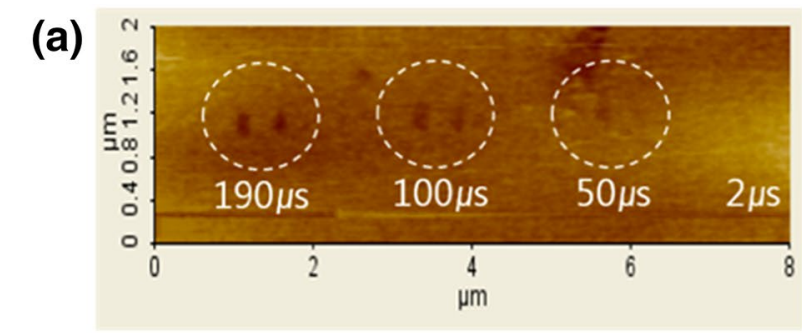

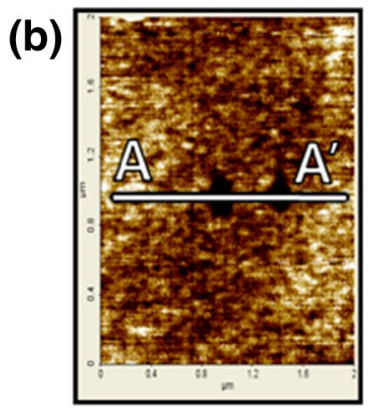

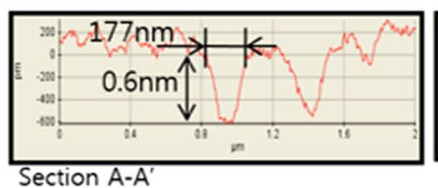

(c)
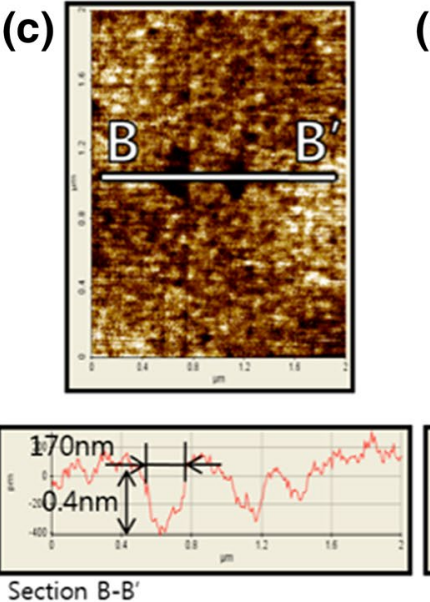

(d)
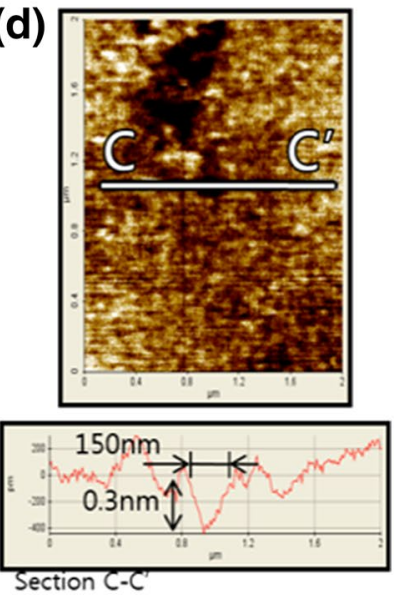
patterns directly over the substrate. Hence, contact and noncontact modes of material removal are possible, and their application must be explored further with improvements to achieve consistent ways of machining.

With Si being a brittle material, machining can be performed in the ductile mode and with this, tens to hundreds of nanometers of depth can be achieved, with less wear resistance using a diamond tip, as reported by Kawasegi et al. [119]. These machining characteristics in the ductile mode and the ductile/brittle transitions can be analyzed to have a clear picture of various mode transitions from plastic deformation to brittle crack during nano-scale machining [120]. Methods such as surface modification by ion implantations can also be implemented to cut Si-like brittle materials such as the softening of tungsten carbide surface, making it easier for machining with improved chip formation and machinability at nanoscale [121]. Even though $\mathrm{Si}$ is hard and brittle, the research above shows that there are possibilities for direct etching that can lead to proper development of Si-based electronic components, which in turn result in its mass production.

\subsection{HOPG: Highly Oriented Pyrolytic Graphite}

HOPG is a variant of graphite synthesized by thermal cracking of hydrocarbons and heat treatment along with pressure to modify the $c$-axis orientation of crystallites [122]. HOPG has a layered surface and is easy to prepare [123, 124], although it is expensive due to the requirements of high temperature and pressure. The cleaning methodology is as simple as using an adhesive tape, such as Scotch tape, to remove the defective layers, which is known as mechanical exfoliation $[125,126]$. It has been reported that an AFM tip can be used to exfoliate HOPG to achieve thickness of $200 \mathrm{~nm}$ [127]. This is possible due to the mechanically weak graphite layers [128]. This method can be used to attain monolayers of graphene from HOPG. These atomically flat and layered structures make HOPG a great candidate for lithography and machining studies [123, 124, 129].

Owing to this flat and uniform surface, the roughness over HOPG is typically low. As a result, the scratches formed over the sample are V-shaped, as reported by Hassani et al. [130]. They have applied forces ranging from 5.5 to $50.5 \mu \mathrm{N}$ and found debris accumulating at the beginning and end of the scratches as the forces increased. They have reported that the rate of tip wear with time and number of scratches was high due to the hard surface of HOPG. Controlled humidity conditions can improve the removal rate and the surface can be etched electrochemically, with less applied force.

Electrochemical etching using AFM tip over HOPG surface to obtain atomic-scale machining has been reported in earlier studies [76, 131, 132]. Since only a few works have been performed on AFM machining over HOPG in recent years, we have mentioned some of the earlier works before 2010. Kim et al. [27] showed that cutting is possible only if the tip is negatively biased, below a threshold. At $-10 \mathrm{~V}$, they achieved a depth of $7.9 \mathrm{~nm}$, which is approximately 23 atomic layers of graphite. They proposed that the cutting mechanism can be implemented by controlling the graphite etching by adjusting the field-emission current originating from the negatively biased tip. Better etching was obtained above $-8 \mathrm{~V}$, as shown in Fig. 6. In their report, the threshold voltage for etching increased with increasing scan speed. Hence, scan speed, loading force, and applied bias contribute largely to the material removal mechanism.

The work performed by Park et al. [132] resulted in achieving nanoholes up to $10 \mathrm{~nm}$ in diameter and $0.34 \mathrm{~nm}$ in depth, which corresponds to a single layer of graphene. In their experiment, voltage of $-10 \mathrm{~V}$ was applied to the metalcoated tip with a 50-ms pulse width. The pressure applied by the tip was found to be $\sim 800 \mathrm{nN}$ with $\sim 20$-nm tip deflection. It should be noted that no debris was formed around the nanoholes after machining. They consider the chemical reaction between the graphite and tunneling electrons to be the machining principle. By maintaining the optimum scratching velocity, force, and other parameters, single-layer material removal can be extended to obtain arbitrary shapes. Similar research was performed by Jiao et al. [76] but they attained grooves of depth up to $17.5 \mathrm{~nm}$ at $-10 \mathrm{~V}$ provided to the tip. Also, the threshold voltage was found to be $-4 \mathrm{~V}$, since there was no etching below this voltage.
Fig. 6 Etched lines over HOPG. a Etched lines over HOPG for different voltages and $\mathbf{b}$ the line profile for the different etched lines showing the depth of each line. Reproduced from Ref. [27]. Copyright American Physical Society
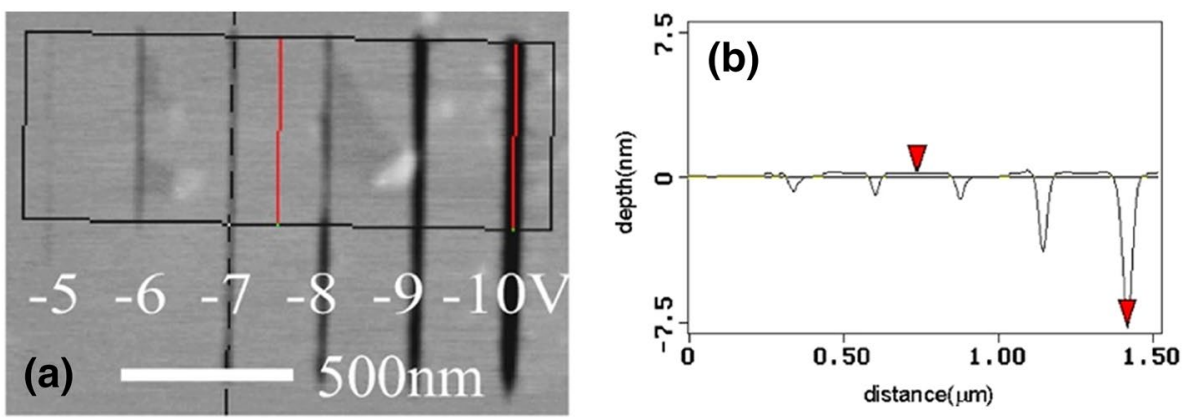
On the contrary, Jiang et al. [50] achieved convex and concave structures over HOPG, depending on the amplitude and duration of voltage pulse. These features were achieved when the tip was placed over different spots, each for a particular voltage pulse, as shown in Fig. 7. In Fig. $7 \mathrm{~d}$, the numbers from 1 to 9 correspond to the voltage pulse of $8 \mathrm{~V}$ applied for durations 100, 200, 500, 1000, 2000, 4000, 6000, 8000, and 10,000 ms. The convex structures were obtained for pulses from 100 to $1000 \mathrm{~ms}$, whereas concave ones were formed from 2000 to $10,000 \mathrm{~ms}$, with exponential increase with the duration. The experiments were performed in a humid environment with $\mathrm{RH} \sim 60 \%$. They applied positive voltage to the substrate, concentrating the electrons on the tip. They also scratched the substrate with different voltages up to $9 \mathrm{~V}$ and a scratching speed of $1 \mu \mathrm{m} / \mathrm{s}$. In their experiment, the threshold to obtain material removal was estimated to be $5-6 \mathrm{~V}$, as shown in Fig. 7a. In their conclusion, the height of convex features depended only slightly on the voltage, while there is a large influence of voltage over the concave features, as the depth increased considerably with increased voltage. According to them, the adsorbed water and oxygen over the graphite facilitated the formation of concave structures, while the oxidation induced by the defects of graphite caused the convex depositions. In 2011, the same authors demonstrated the transition from the convex to concave features over HOPG beyond a threshold voltage, which ranged between 4.1 and $5 \mathrm{~V}$ [25].
Similarly, protrusions and trench features were observed on HOPG by Gowthami et al. [133] in 2013 by LAO. They also grounded the tip and the humidity was maintained between $55 \%$ and $60 \%$. They observed the changes happening on the substrate over different days. The patterns they obtained were reported to have a widening and reduction in width over a day's time. They explained this change as a result of water adsorption by the LAO-modified region and the subsequent evaporation with time or the sweeping effect of AFM scanning. These types of research are important to develop stable and robust atomic-scale devices in the future.

An important factor in atomic-scale manufacturing is the ability to control the machining of samples. This includes the effects of machining performance on fabrication mechanism and transition from LAO to electrical breakdown during lithography. Yang and Lin [131] performed such an experiment to understand the machining performance and the transitions like the above mentioned on HOPG. They have used a Si probe coated with conductive TiN films. The humidity provided was in the range of $50 \%$ to $55 \%$. HOPG sample was given voltages up to $10 \mathrm{~V}$, keeping the tip grounded. They evaluated the I-V curves with feedback on and off. Their results showed that when the feedback was on, a gradual increase of current till $4 \mathrm{~V}$, as from the linear curve, and a rapid increase in current flow above $5.5 \mathrm{~V}$, as in the exponential curve, was observed. Hence, the transition region was found to be in the range of $4-5.5 \mathrm{~V}$, as shown in Fig. 8. On
Fig. 7 Formation of nano holes over HOPG. a The scratched lines, $\mathbf{b}$ the line profile, $\mathbf{c}$ the surface of HOPG before machining, and $\mathbf{d}$ the nanoholes obtained for pulse durations from 100 to $10,000 \mathrm{~ms}$, which is noted by numbers from 1 to 9. Reproduced from Ref. [50]. Copyright IOP Publishing
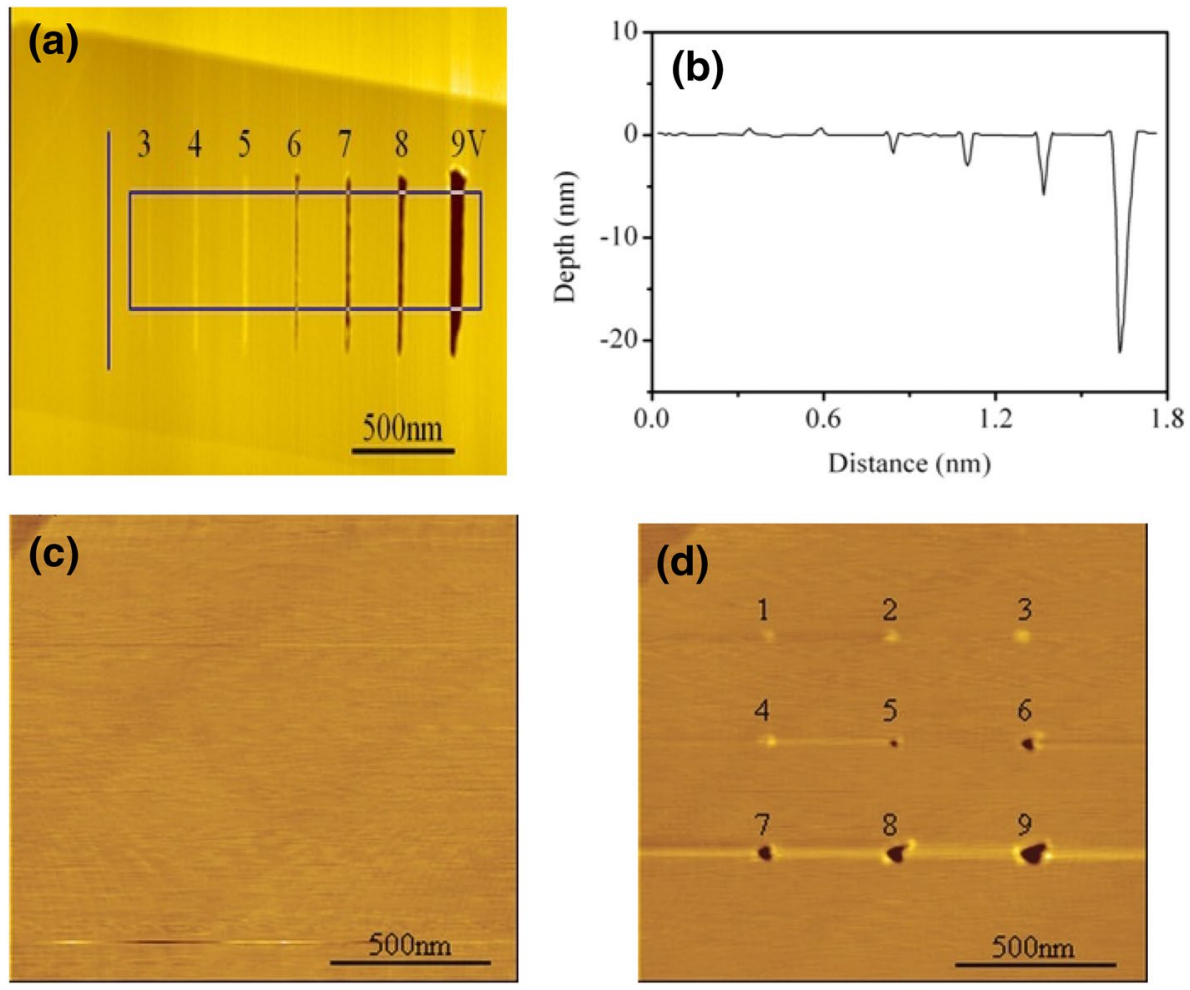


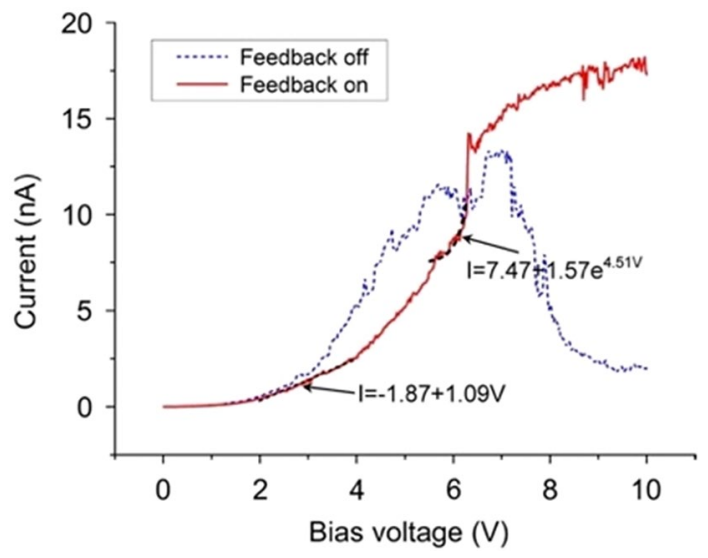

Fig. 8 The I versus $\mathrm{V}$ curve showing the transition from local anodic oxidation to the breakdown region when the feedback was on and off. Reproduced from Ref. [133]. Copyright Microscopy Society of America 2016

the other hand, when the feedback was off, there was a rapid decrease in the current flow above $5.5 \mathrm{~V}$. They also etched HOPG, with applied bias of $4 \mathrm{~V}$ and a scan speed of $2 \mu \mathrm{m} / \mathrm{s}$, attaining a depth of $0.9 \mathrm{~nm}$ and width of $100 \mathrm{~nm}$, which is close to three graphene layers.

Another work by Kurra et al. [134] succeeded in fabricating mesoscopic graphitic island (MGI) over HOPG by local electrochemical oxidation and etching using AFM tip. These MGIs could store charges, which were stable over time. They have reported that at a voltage of $-8 \mathrm{~V}$ and humidity of $35 \%$, the HOPG surface could be oxidized with tapping AFM mode and could be etched with contact mode of operation. They have achieved oxide deposits as high as $1 \mathrm{~nm}$ with tapping mode and a depth of $1.5 \mathrm{~nm}$ in the contact mode, which is comparable with that reported in Ref. [50].

With graphene being a widely used material for electronic applications [28, 135-138], machining HOPG using AFM could bring about breakthrough research in atomic-scale device fabrication.

\subsection{Gold: A Universal Reference Material for Moletronics}

Gold is an important material and used as a reference for molecular electronic studies [87, 139]. Most of the theoretical works for developing atomic-scale electronic components are performed considering gold as the electrode material [108, 122, 139-144]. Apart from this, the properties and structures of gold in different orientations have been studied in detail by many researchers both in ultra-high vacuum (UHV) and electrochemical environments [145]. Scanning probe microscopes have been used for machining Au nanowires in the earlier years [146, 147]. Hence, machining Au in atomic precision can bring about drastic development in the experimental realities, and in the manufacturing sector.

It has already been discussed that the tunneling current passing between the AFM tip and the substrate can cause oxide structures, which can act as potential barrier regions in the electronic transport studies [148]. Li et al. [149] achieved nanochannels and nanopatterns over gold nanowires manufactured on silicon wafer, with the combination of nanoindenter and AFM. These nanochannels were created using a sharp diamond tip. No debris was formed after scratching the gold surface. They have achieved nanochannels of $170 \mathrm{~nm}$ length and a depth of $5 \mathrm{~nm}$, as shown in Fig. 9a. They have also shown that complex patterns can be obtained over Au combining nanoindentation and nanochannel formation, as shown in Fig. 9b.

Similar grooves are achieved by Fang et al. [150] by scratching the $\mathrm{Au}$ and platinum surfaces with a diamond AFM tip in ambient air conditions. In their experiment, they have used a pyramidal-shaped diamond tip with an apex angle of $60^{\circ}$ and tip radius of $15 \mathrm{~nm}$. According to their report, the depth of grooves for Au was greater than platinum. They scratched the surface with different applied forces, from $0.5 \mu \mathrm{N}$, with an increment of $0.5 \mu \mathrm{N}$, to $2 \mu \mathrm{N}$, and the depth increased with increasing force, as shown in Fig. 10a. With further increase in force up to $7.5 \mu \mathrm{N}$, the wear mark increased, as shown in Fig. 10b. The increase in wear depth over Au due to the increased force shows the
Fig. 9 a Nanochannel formed with a depth of $5 \mathrm{~nm}$ and $\mathbf{b}$ the combined nanochannel and nanoindentation formation. Reproduced from Ref. [147]. Copyright IOP Publishing
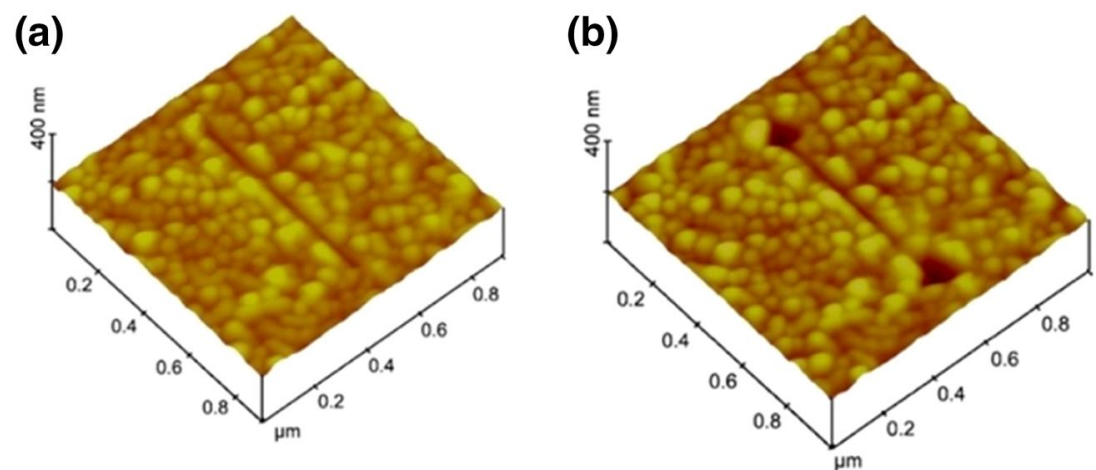
Fig. 10 Material removal over $\mathrm{Au}$. a The material removal obtained for different applied forces over $\mathrm{Au}$ and $\mathbf{b}$ the increasing wear depth corresponding to the force applied over Au. Reproduced from Ref. [148]. Copyright Elsevier
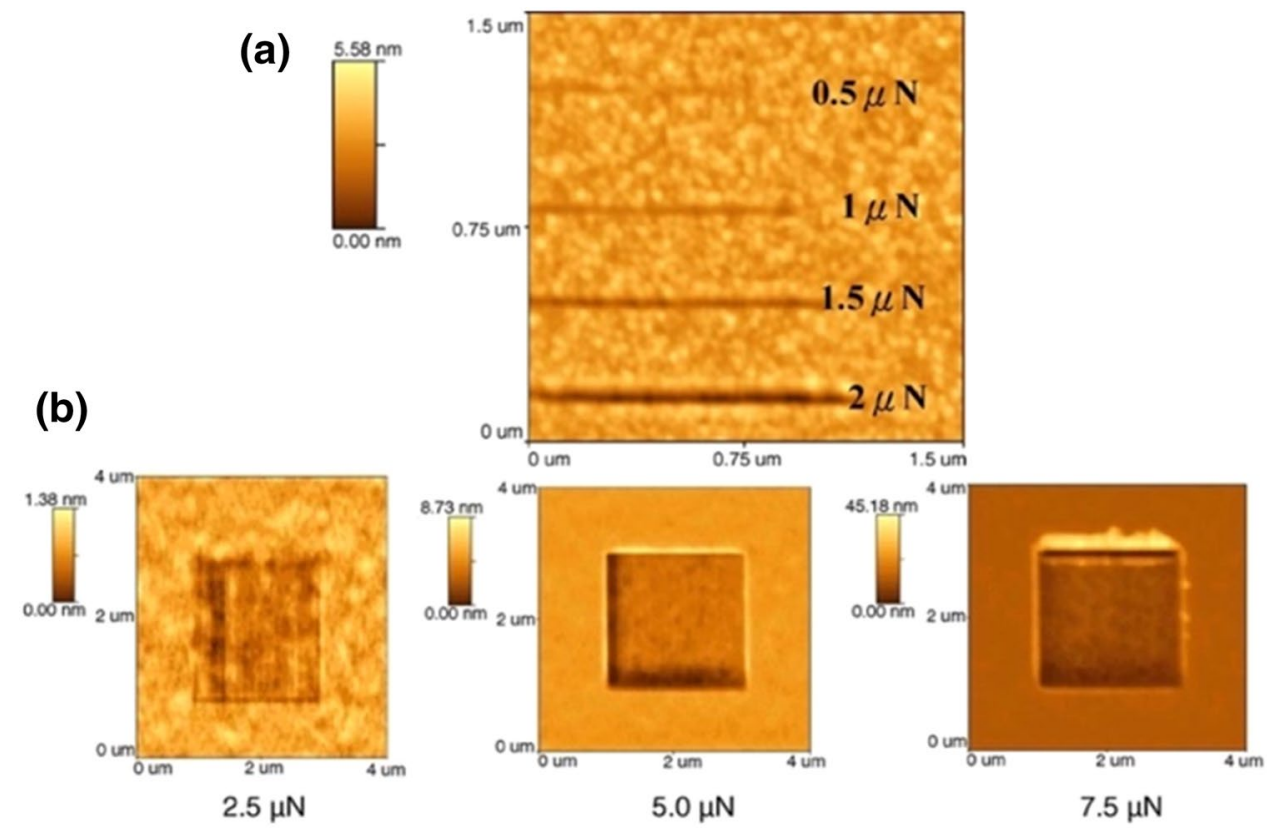

possibilities of removing single atomic layers with optimum parameters.

In the mentioned research, no voltage was applied to the AFM tip and the sample. Instead, they have applied different loads to achieve different depths; hence it is a mechanical method of material removal. Therefore, the effects of applying voltage across the tip-sample junction should be explored to understand the effects of oxide formation or the material removal mechanism over $\mathrm{Au}$ substrate. This might be useful in enabling better removal rate from the $\mathrm{Au}$ surface. Other options such as using a counter material as the AFM tip other than diamond can also be implemented, which makes it cost-effective and efficient. In this way, much more research can be carried out on this material.

AFM-based machining research on $\mathrm{Au}$ is lacking at this stage. From the above-mentioned studies, most of them are related to the fabrication of Au nanowires. An electrochemical AFM etching methodology on Au is lacking, and is an open field of research, even though etching on Au within nanoshaved self-assembled monolayers with the aid of AFM has been reported [151]. Also, Au is malleable and not ideal, making it a challenge for machining purposes. Hence, electrochemical approaches are needed for these reasons.

\subsection{Silicon Carbide: A Wide Bandgap Semiconductor}

$\mathrm{SiC}$ is a semiconductor having a wide bandgap [152]. They have different applications because of their physical and electronic properties. They have been used in high-power, high-frequency, and high-temperature devices due to their excellent thermal and electrical conductivity [153]. Even though they are hard, SiC semiconductors can have higher wear rates than other conventional abrasives [154].

$\mathrm{SiC}$ has different crystal plane orientations such as a-, $\mathrm{m}-$, and c- planes, each differing in their properties related to the etching, thermal oxidations, and bulk growth [78, 155-158]. The oxide growth using an AFM tip over different planes of $4 \mathrm{H}-\mathrm{SiC}$ was studied by Ahn et al. [78], who found that oxides can be grown as high as 6.5 and $13 \mathrm{~nm}$, respectively, for a- and m- planes, while 30-nm oxide height can be achieved over the c-plane. These authors have used a conductive Si tip and a humidity of $\sim 40 \%$, with a scan speed of $0.5 \mu \mathrm{m} / \mathrm{s}$ to scratch over the substrate. However, these oxide structures were not treated with any solutions to find the possibilities of material removal from the SiC surface.

Similarly, Lorrenzoni and Torre [79] achieved oxide patterns over $6 \mathrm{H}-\mathrm{SiC}(0001)$ by field induced oxidation (FIO). They have adjusted the oxide height and thickness by varying the voltage and pulse duration. On the contrary to Ref. [78], they have treated the substrate with HF solution to remove the oxide deposits from the surface. On the contrary to Ref. [78], they have treated the substrate with HF solution to remove the oxide deposits from the surface. In their experiment, a humidity range of $20 \%-45 \%$ and negative bias to the tip were provided. The lines were achieved between 5 and $15 \mathrm{~V}$, with a scratching speed of $1 \mu \mathrm{m} / \mathrm{s}$, as shown in Fig. 11. They obtained a lateral feature of $\sim 50 \mathrm{~nm}$ and a full width at half maximum (FWHM) $350 \mathrm{~nm}$. Figure 11 a shows the patterns formed over $\mathrm{SiC}$ when a $10-\mathrm{V}$ bias and a scratching speed of $1 \mu \mathrm{m} / \mathrm{s}$ were implemented. When these patterns were treated in $5 \%$ aqueous $\mathrm{HF}$ for $30 \mathrm{~s}$, depressions of $\sim 3 \mathrm{~nm}$ were obtained, as shown in Fig. $11 \mathrm{~b}$. The height profile of the untreated $\mathrm{SiC}$ and the HF-treated 
Fig. 11 Patterns over SiC. a The oxide patterns formed over $6 \mathrm{H}-\mathrm{SiC}$ at different bias voltage and the line profile showing the height of each deposits in $\mathrm{nm}$. b The 3D structures fabricated over $\mathrm{SiC}$. c The depressions obtained when the same surface was treated with HF solution. d The height profile for the surface before and after treating with HF solution. Reproduced from Ref. [71]. Copyright AIP Publishing

(a)
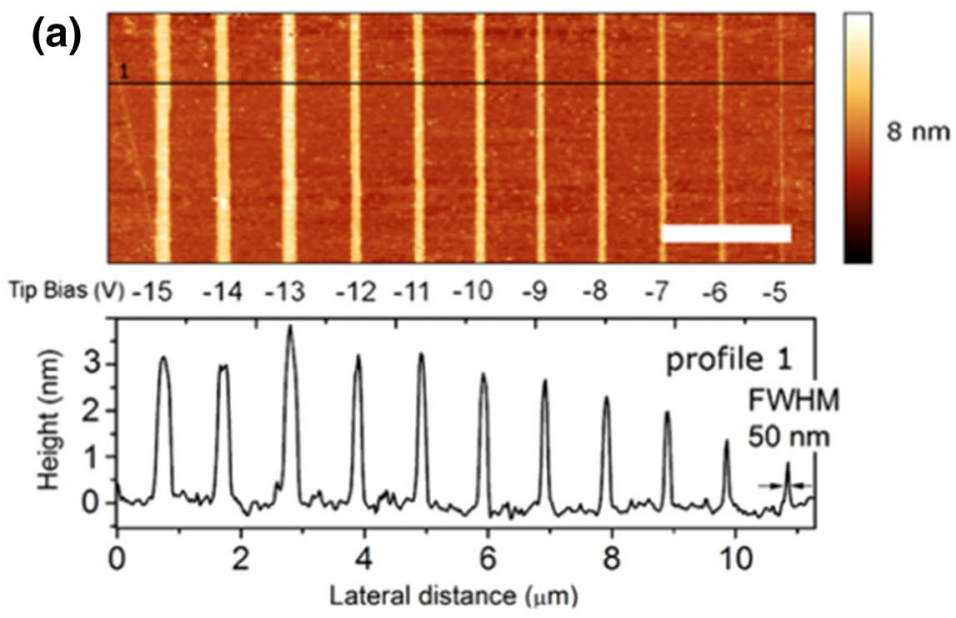

(b)

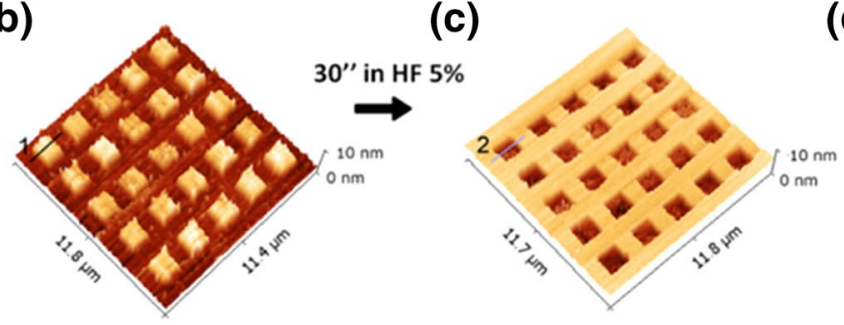

(d)

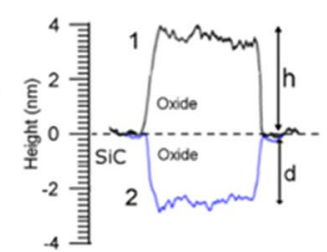

surface is shown in Fig. 11c. In the figure, $h$ represents the oxide height and $d$ represents the HF etched depth.

Since $\mathrm{SiC}$ is a hard material with extreme stiffness and micro hardness, machining the surface with atomic precision is a difficult task [159-161], even though scratching with a Berkovich indenter has been performed by Zhang et al. [162]. However, an effective AFM-based machining of SiC is still lacking, though nanopatterning of epitaxial graphene grown on $\mathrm{SiC}(0001)$ has been reported by Alaboson et al. [22] using c-AFM. Recently, a molecular model showing the different aspects of tip-based machining over single-crystal $\mathrm{SiC}$ has been performed by Meng et al. [163].

The material properties of $\mathrm{SiC}$ and Si differ in many ways; this can be referred from Table $1 . \mathrm{SiC}$ is much harder than $\mathrm{Si}$, with a Mohs hardness of 9-10. The fracture toughness and tensile strength are also much harder for $\mathrm{SiC}$ than Si. Owing to these factors, limited research on AFM-based material removal is performed on $\mathrm{SiC}$. Apart from this, $\mathrm{SiC}$ is very brittle and diamond grinding techniques are well favored for proper machining. In the studies performed so far, as shown in Table 2, Pt-coated AFM probes are used. Hence, $\mathrm{SiC}$ needs to be explored further for the applications in atomic-scale device fabrication. As mentioned above, limited research has been conducted using $\mathrm{SiC}$ as a sample material for AFM-based machining for the above-mentioned reasons. Si probes have been used to test their durability over $\mathrm{SiC}$ [97] but a consistent material removal method should be developed and tested to expand the research possibilities with this material. In addition, $\mathrm{SiC}$ has a standard etching procedure that provides an atomically flat surface, with atomic step edges, and hence finding the parameter space to achieve this locally should be the goal of future research.

\section{Research Trends and Future Outlook}

From the works conducted so far, researchers are on the verge of making a breakthrough by enabling the mass production of atomic-scale devices to improve the efficiency and access to the technology. The next generation of manufacturing is known as Manufacturing III, which is at the atomic scale [164, 165]. Currently, molecular dynamics simulations are best suited for studying the possibilities of material removal mechanisms [166-170]. These simulations help to visually analyze the interactions occurring at the atomic scale. Once the fundamentals are developed and properly simulated, experimental realities are possible, which can eventually lead to the fabrication and integration of these devices in IC chips. The most advanced AFM-based manufacturing is performed with the help of artificial intelligence (AI) technology [35]. Machine learning can bring about drastic innovations since automation is a key factor in achieving atomic fabrication with precision.

The mechanical material removal over Si has achieved a removal thickness of merely $1.4 \pm 0.3 \AA$, which is very close to a single layer of monocrystalline $\mathrm{Si}$. However, consistent and stable removal has not yet been achieved. Apart from this, the formation of oxide deposits can be considered 
Table 2 Summarized results from the selected papers mentioned in this review along with some of the parameters used in etching over Si, $\mathrm{HOPG}$, and $\mathrm{SiC}$

\begin{tabular}{|c|c|c|c|c|c|c|}
\hline Substrate & Tip & $\operatorname{Bias}^{\mathrm{a}}(\mathrm{V})$ & Loading force $(\mu \mathrm{N})$ & $\mathrm{ED}^{\mathrm{b}}(\mathrm{nm})$ & $\mathrm{RH}$ & Refs. \\
\hline P-type $\operatorname{Si}(100)$ & DLC & - & $10-20$ & $0.68-3.35$ & Room cond. & {$[86]$} \\
\hline Bare Si surface & Diamond & - & $31.11-155.55$ & $6.09-36.1$ & Room cond. & [112] \\
\hline $\operatorname{Si}(100)$ & Diamond-coated tip & - & $10-110$ & 18 & Room cond. & [120] \\
\hline p-type $\operatorname{Si}(110)$ & Single-crystal diamond tip & - & 2.80 & 5.1 & Room cond. & [113] \\
\hline p-type $\operatorname{Si}(100)$ & NSC18/Ti-Pt-coated probe & 8 & $\mathrm{NC}^{\mathrm{c}}(0.1$ and $0.2 \mu \mathrm{m}$ gap $)$ & 0.3 & $70 \%-75 \%$ & [93] \\
\hline $\begin{array}{l}\text { Boron doped p-type (100) } \\
\text { silicon on insulator wafer }\end{array}$ & Au-coated and $\mathrm{Cr} / \mathrm{Pt}$-coated tips & $8-9$ & $0.1-0.2 \mathrm{~N}$ & 44.71 & $50 \%-80 \%$ & [110] \\
\hline Boron-doped p-type Si(100) & $\mathrm{Pt} / \mathrm{Ti}$-coated Si probe & $0-2$ & 2 & 0.8 & In DI water & [48] \\
\hline $\operatorname{Si}(100)$ & Silica microsphere probe & - & 0.3 & 0.14 & $75 \% \pm 2 \%$ & {$[6]$} \\
\hline HOPG & $\mathrm{Cr} / \mathrm{Au}$-coated Si tip & 10 & 0.8 & 0.34 & Room cond. & [132] \\
\hline HOPG & NSC21/Ti-Pt tip & $0-10$ & - & 17.5 & $30 \%$ & [76] \\
\hline HOPG & Pt/Ir-coated Si tip & $0-12$ & 0.25 & 1.5 & $30 \%-50 \%$ & [134] \\
\hline HOPG & SCM-PIT (Pt/Ir) tip & 8 & 15 & 15 & $58 \%$ & [133] \\
\hline HOPG & Conductive TiN-coated Si probe & $0-10$ & $0.1-0.2$ & 0.9 & $50 \%-55 \%$ & [131] \\
\hline HOPG & Conductive Rh coated & 8 & - & 0.576 & $60 \%$ & {$[50]$} \\
\hline Epitaxial graphene on $\mathrm{SiC}$ & cAFM tip & $0-10$ & - & 1.2 & $35 \%$ & {$[22]$} \\
\hline $4 \mathrm{H}-\mathrm{SiC}$ & $\mathrm{Pt} / \mathrm{Ir}$-coated conductive $\mathrm{Si}$ & $6-10$ & 0.1 & - & $40 \%$ & [78] \\
\hline $6 \mathrm{H}-\mathrm{SiC}(0001)$ & Pt-coated probe & $5-13$ & - & 3 & $20 \%-45 \%$ & [79] \\
\hline
\end{tabular}

${ }^{\text {a }}$ The tip is grounded and the sample is given positive bias

${ }^{\mathrm{b}}$ Etched depth

${ }^{\mathrm{c}} \mathrm{NC}$-non contact; (-) Information not available from the manuscript

a possibility in controlling the depth of Si removal. From the papers mentioned above, many factors such as voltage, scratching speed, and so on can influence this deposition. Finding optimal parameters to remove the thinnest possible layers electrochemically from the substrate is still an open field of research. The tip material can also be selected appropriately to achieve maximum removal with less wear. Currently, diamond tips are the most favored, as diamond is much harder than other materials. To solve the highcost problem, DLC-coated tips are also successively used, which is almost as hard as diamond but less expensive at the expense of a larger tip size. In addition, metal-doped tips are also used, which are cheap and durable for academic research purposes. For future works based on electrochemical AFM-based etching, conductive tips are best suited, as they require a strong electric field to overcome the activation energy required for the oxidation reactions to take place. Si probes with PtIr $_{5}$ coatings are commonly used for this purpose.

In the case of HOPG, $\mathrm{Au}$, and $\mathrm{SiC}$ substrates, there is much more research to be explored to find the possibilities of atomic manufacturing. In the future, a large area deposition of few layers of graphene could be implemented, from which a single layer can be removed. Even though etching has been achieved, AFM-based machining is still lacking, and if a successful removal methodology is achieved, many applications in moletronics and molecular electronic device fabrication can be made possible. Towards the future, a single atomic protrusion from the electrode should be fabricated for connecting with the terminal of a molecule. This is a tedious task, but possible with a systematic and careful approach.

The theoretical thickness of a monolayer of Si (100) is $\sim 1.36 \AA$ [6]. Likewise, a single layer of HOPG corresponds to $3.40 \AA$ [132]. This should be the target layer thickness to achieve ACSM on these materials. Table 2 shows a summary of the etch depth achieved, including the major parameters used by different researchers to achieve ACSM on Si, HOPG, and $\mathrm{SiC}$. From the table, it is evident that p-type $\mathrm{Si}(100)$ is mostly used as the substrate for the experiments. Also, diamond tips are the most favored due to their hardness, durability, and less tip wear. The minimum layer removed on $\mathrm{Si}$ is claimed to be $0.14 \mathrm{~nm}$, which is almost close to a monolayer thickness, as mentioned earlier. The force applied depends mostly on the tip used. For diamond- and DLC-coated tips, higher forces are required, ranging from 10 to $160 \mu \mathrm{N}$, even though low forces on orientations such as $\mathrm{Si}$ (110) have been reported [113], whereas low loading forces can be applied for metal-coated tips. NC-AFM also finds its application in ACSM of $\sim 0.3 \mathrm{~nm}$ material removal. Hence, $\mathrm{Si}$ and Si-like materials can be machined efficiently by using hard tips such as diamond 
with higher loading force, with voltages ranging from 1 to $10 \mathrm{~V}$ and by providing $\mathrm{RH}$ ranging between $50 \%$ and $80 \%$.

In the case of HOPG, due to its soft surface compared to $\mathrm{Si}$, diamond tips can be replaced with metal-coated tips such as $\mathrm{Pt} /$ $\mathrm{Ir}, \mathrm{Cr} / \mathrm{Au}$, or TiN. Experiments can be performed in room conditions, however, a humid environment with humidity ranging between $30 \%$ and $60 \%$ is optimal. Apart from this, less loading force ranging between 0.1 and $1 \mu \mathrm{N}$ is mostly sufficient to scratch the HOPG surface. Further research is yet to be conducted over $\mathrm{SiC}$ and $\mathrm{Au}$, however, from the research performed so far, Pt-coated tips with applied bias between 6 and $13 \mathrm{~V}$ and humidity conditions ranging between $20 \%$ and $\sim 50 \%$ can be used for machining $\mathrm{SiC}$.

For the electrochemical approach, no special electrolytes are needed, since the water meniscus formed between the tip and the substrate serves the purpose. However, different electrolytes could be explored for achieving selectivity and reducing byproducts or oxidation deposition. Humidity is maintained between $20 \%$ and $80 \%$ in most of the research. Based on the previous studies, a humid environment is much more favored for electrochemical etching process by AFM tip. Also, voltage should be provided to enhance the electric field between the tip and sample. Hence, optimum parameters can work towards achieving atomic-scale manufacturing over these substrates.

Optical excitation is another area to be explored to enhance the etching of materials. The photogenerated carriers in a plasmonic structure could facilitate reactions which could aid the material removal mechanism. Optical excitations are proved to alter the structure and properties of materials [171]. As a matter of fact, conventional classical mechanical theory is insufficient to deal with interactions at the atomic scale. As small-scale manufacturing is very sensitive, a well-defined quantum mechanical approach is required since the tunneling effect and the possible underlying damage which occurs can hinder the machining. Without confining only to silicon, further materials such as copper should be explored for this approach [172]. The major problem lies in the mass production of these manufactured products. AFM is a medium to perform the analysis and research, but it is not a proper machining platform for the mentioned purpose, even in a millipede configuration [173]. Machines capable of performing small-scale manufacturing should be developed with proper supervision of the quality and performance of machined components through surface integrity research and development [174].

\section{Conclusions}

In this review, we have come across different aspects of research performed to achieve atomic-scale manufacturing using AFM-based machining, emphasizing the past decade.
Four typical materials having potential applications in the semiconductor industry have been selected: these are $\mathrm{Si}$, HOPG, Au, and SiC. Out of these, most of the research, based on AFM machining, has been conducted on $\mathrm{Si}$. The formation of oxide deposits over $\mathrm{Si}$ and $\mathrm{SiC}$ and the formation of grooves on HOPG and Au are described in detail with the reactions taking place at the tip-substrate junction. Since many reviews have reported on tip-based manufacturing, we have only concentrated on limited and much mentionable works on electrochemical and some mechanical works with the application of AFM over the mentioned substrates. In conclusion, we could state that a stable and continuous atomic-scale manufacturing on $\mathrm{Si}$, exploring much more possibilities on HOPG, Au, and SiC, should be the aim, leading towards ACSM in the future.

Acknowledgements The authors acknowledge the support of the Science Foundation Ireland (SFI) (Nos. 15/RP/B3208 \& SFI/17/ CDA/4637); and '111' project by the State Administration of Foreign Experts Affairs and the Ministry of Education of China (No. B07014).

Open Access This article is licensed under a Creative Commons Attribution 4.0 International License, which permits use, sharing, adaptation, distribution and reproduction in any medium or format, as long as you give appropriate credit to the original author(s) and the source, provide a link to the Creative Commons licence, and indicate if changes were made. The images or other third party material in this article are included in the article's Creative Commons licence, unless indicated otherwise in a credit line to the material. If material is not included in the article's Creative Commons licence and your intended use is not permitted by statutory regulation or exceeds the permitted use, you will need to obtain permission directly from the copyright holder. To view a copy of this licence, visit http://creativecommons.org/licenses/by/4.0/.

\section{References}

1. McDermott KJ, Yao WA (1997) Developing a hybrid programmable logic controller platform for a flexible manufacturing system. Int J Flex Manuf Syst 9:367-374. https://doi. org/10.1023/A:1007921129376

2. Riordan M, Hoddeson L, Herring C (1999) The invention of the transistor. In: Bederson B (ed) More things in heaven and earth. Springer, New York, pp 563-578. https://doi. org/10.1007/978-1-4612-1512-7_37

3. Kaldasch J (2014) Evolutionary model of Moore's law. ISRN Economics 2014:1-7. https://doi.org/10.1155/2014/781623

4. Tardi C (2019) Moore's Law. https://www.cnet.com/news/moore s-law-to-roll-on-for-another-decade/. Accessed 13 April 2020

5. Binnig G, Quate CF, Gerber CH (1986) Atomic force microscope. Phys Rev Lett 56:930-933. https://doi.org/10.1103/PhysR evLett.56.930

6. Chen L, Wen J, Zhang P, Yu B, Chen C, Ma T et al (2018) Nanomanufacturing of silicon surface with a single atomic layer precision via mechanochemical reactions. Nat Commun 9:1542. https://doi.org/10.1038/s41467-018-03930-5

7. Santinacci L, Zhang Y, Schmuki P (2005) AFM scratching and metal deposition through insulating layers on silicon. Surf Sci 597:11-19. https://doi.org/10.1016/j.susc.2005.05.069 
8. Yan YD, Hu ZJ, Liu WT, Zhao XS (2015) Effects of scratching parameters on fabrication of polymer nanostructures in atomic force microscope tapping mode. Proc CIRP 28:100-105. https ://doi.org/10.1016/j.procir.2015.04.017

9. Ogino T, Nishimura S, Shirakashi J (2008) Scratch nanolithography on Si surface using scanning probe microscopy: influence of scanning parameters on groove size. Jpn J Appl Phys 47:712714. https://doi.org/10.1143/JJAP.47.712

10. Brousseau EB, Krohs F, Caillaud E, Dimov S, Gibaru O, Fatikow S (2010) Development of a novel process chain based on atomic force microscopy scratching for small and medium series production of polymer nanostructured components. J Manuf Sci Eng 132:030901. https://doi.org/10.1115/1.4001481

11. Zhang F, Edwards D, Deng X, Wang Y, Kilpatrick JI, BassiriGharb N et al (2020) Investigation of AFM-based machining of ferroelectric thin films at the nanoscale. J Appl Phys 127:034103. https://doi.org/10.1063/1.5133018

12. Geng Y, Yan Y, Xing Y, Zhao X, Hu Z (2013) Modelling and experimental study of machined depth in AFM-based milling of nanochannels. Int J Mach Tool Manuf 73:87-96. https://doi. org/10.1016/j.ijmachtools.2013.07.001

13. Yan Y, Chang S, Wang T, Geng Y (2019) Scratch on polymer materials using AFM tip-based approach: a review. Polymers 11:1590. https://doi.org/10.3390/polym 11101590

14. Garcia R, Knoll AW, Riedo E (2014) Advanced scanning probe lithography. Nat Nanotechnol 9:577-587. https://doi. org/10.1038/nnano.2014.157

15. Keyvani A, Tamer MS, van Es MH, Sadeghian H (2016) Simultaneous AFM nano-patterning and imaging for photomask repair. In: Proc. SPIE 9778, Metrology, inspection, and process control for microlithography, vol XXX, p 977818. https://doi. org/10.1117/12.2219041

16. Deng J, Zhang L, Dong J, Cohen PH (2016) AFM-based 3D nanofabrication using ultrasonic vibration assisted nanomachining. J. Manuf. Process 24:195-202. https://doi.org/10.1016/j. jmapro.2016.09.003

17. Moldovan A, Marinescu A, Brajnicov S, Dumitrescu N, Scarisoreanu ND, Dinescu M (2019) Scanning probe techniques for nanoscale imaging and patterning. In: Dinca V, Sucia MP (eds) Functional nanostructured interfaces for environmental and biomedical applications. Elsevier, Amsterdam, pp 97-112. https:// doi.org/10.1016/B978-0-12-814401-5.00005-0

18. Maver U, Velnar T, Gaberšček M, Planinšek O, Finšgar M (2016) Recent progressive use of atomic force microscopy in biomedical applications. TrAC Trend Anal Chem 80:96-111. https://doi. org/10.1016/j.trac.2016.03.014

19. Hu J, Zhang Y, Gao H, Li M, Hartmann U (2002) Artificial DNA patterns by mechanical nanomanipulation. Nano Lett 2:55-57. https://doi.org/10.1021/n10156336

20. Firtel M, Henderson G, Sokolov I (2004) Nanosurgery: observation of peptidoglycan strands in Lactobacillus helveticus cell walls. Ultramicroscopy 101:105-109. https://doi.org/10.1016/j. ultramic.2004.05.009

21. Morita S, Wiesendanger R, Meyer E (2002) Noncontact atomic force microscopy. Springer, Berlin. https://doi.org/10.1007/9783-642-56019-4

22. Alaboson JMP, Wang QH, Kellar JA, Park J, Elam JW, Pellin MJ et al (2011) Conductive atomic force microscope nanopatterning of epitaxial graphene on $\mathrm{SiC}(0001)$ in ambient conditions. Adv Mater 23:2181-2184. https://doi.org/10.1002/adma.201100367

23. Garcia R, Martinez RV, Martinez J (2006) Nano-chemistry and scanning probe nanolithographies. Chem Soc Rev 35:29-38. https://doi.org/10.1039/B501599P

24. Kinser CR, Schmitz MJ, Hersam MC (2005) Conductive atomic force microscope nanopatterning of hydrogen-passivated silicon in inert organic solvents. Nano Lett 5:91-95. https://doi. org/10.1021/n1048275q

25. Jiang Y, Guo W (2011) Convex-concave nanostructure transition on highly oriented pyrolitic graphite surface induced by atomic force microscope tip under bias voltage. J Exp Nanosci 6:96-101. https://doi.org/10.1080/17458081003752970

26. Wei Z, Wang D, Kim S, Kim S-Y, Hu Y, Yakes MK et al (2010) Nanoscale tunable reduction of graphene oxide for graphene electronics. Science 328:1373-1376. https://doi.org/10.1126/ science. 1188119

27. Kim D-H, Koo J-Y, Kim JJ (2003) Cutting of multiwalled carbon nanotubes by a negative voltage tip of an atomic force microscope: a possible mechanism. Phys Rev B 68:113406. https:// doi.org/10.1103/PhysRevB.68.113406

28. Giesbers AJM, Zeitler U, Neubeck S, Freitag F, Novoselov KS, Maan JC (2008) Nanolithography and manipulation of graphene using an atomic force microscope. Solid State Commun 147:366-369. https://doi.org/10.1016/j.ssc.2008.06.027

29. Masubuchi S, Ono M, Yoshida K, Hirakawa K, Machida T (2009) Fabrication of graphene nanoribbon by local anodic oxidation lithography using atomic force microscope. Appl Phys Lett 94:082107. https://doi.org/10.1063/1.3089693

30. Weng L, Zhang L, Chen YP, Rokhinson LP (2008) Atomic force microscope local oxidation nanolithography of graphene. Appl Phys Lett 93:093107. https://doi.org/10.1063/1.2976429

31. Buckwell M, Ng WH, Hudziak S, Mehonic A, Lanza M, Kenyon AJ (2019) Improving the consistency of nanoscale etching for atomic force microscopy tomography applications. Front Mater 6:203. https://doi.org/10.3389/fmats.2019.00203

32. Steffes JJ, Ristau RA, Ramesh R, Huey BD (2019) Thickness scaling of ferroelectricity in $\mathrm{BiFeO}_{3}$ by tomographic atomic force microscopy. Proc Natl Acad Sci 116:2413-2418. https:// doi.org/10.1073/pnas.1806074116

33. Custance O, Perez R, Morita S (2009) Atomic force microscopy as a tool for atom manipulation. Nature Nanotech 4:803-810. https://doi.org/10.1038/nnano.2009.347

34. Yan Y, He Y, Geng Y, Hu Z, Li H (2016) Review on AFM tipbased mechanical nanomachining: the influence of the input machining parameters on the outcomes. CNANO 12:666-675. https://doi.org/10.2174/1573413712666160527151032

35. Rashidi M, Wolkow RA (2018) Autonomous scanning probe microscopy in situ tip conditioning through machine learning. ACS Nano 12:5185-5189. https://doi.org/10.1021/acsna no. 8 b02208

36. Fang FZ, Zhang N, Guo D, Ehmann K, Cheung B, Liu K et al (2019) Towards atomic and close-to-atomic scale manufacturing. Int J Extrem Manuf 1:012001. https://doi.org/10.1088/26317990/ab0dfc

37. Gozen BA, Ozdoganlar OB (2010) A rotating-tip-based mechanical nano-manufacturing process: nanomilling. Nanoscale Res Lett 5:1403-1407. https://doi.org/10.1007/s11671-010-9653-7

38. Miyake S, Wang M, Kim J (2014) Silicon nanofabrication by atomic force microscopy-based mechanical processing. J Nanotechnol 2014:1-19. https://doi.org/10.1155/2014/102404

39. Miyake S, Kim J (2001) Fabrication of silicon utilizing mechanochemical local oxidation by diamond tip sliding. Jpn J Appl Phys 40:L1247-L1249. https://doi.org/10.1143/JJAP.40.L1247

40. Miyake S, Kim J (2005) Nanoprocessing of silicon by mechanochemical reaction using atomic force microscopy and additional potassium hydroxide solution etching. Nanotechnology 16:149-157. https://doi.org/10.1088/0957-4484/16/1/029

41. Li Y, Maynor BW, Liu J (2001) Electrochemical AFM "Dip-Pen" nanolithography. J Am Chem Soc 123:2105-2106. https://doi. org/10.1021/ja005654m

42. Reggente M, Passeri D, Rossi M, Tamburri E, Terranova ML (2017) Electrochemical atomic force microscopy: in situ 
monitoring of electrochemical processes, Rome, Italy, p 020009. https://doi.org/10.1063/1.4997138

43. Fang FZ, Zhang XD, Gao W, Guo YB, Byrne G, Hansen HN (2017) Nanomanufacturing - perspective and applications. CIRP Ann 66:683-705. https://doi.org/10.1016/j.cirp.2017.05.004

44. Göbel H (1995) Atomic force microscope as a tool for metal surface modifications. J Vac Sci Technol B 13:1247. https://doi. org/10.1116/1.588245

45. Geng Y, Li H, Yan Y, He Y, Zhao X (2019) Study on material removal for nanochannels fabrication using atomic force microscopy tip-based nanomilling approach. P I Mech Eng B-J Eng 233:461-469. https://doi.org/10.1177/0954405417748188

46. Xue B, Geng Y, Wang D, Sun Y, Yan Y (2019) Improvement in surface quality of microchannel structures fabricated by revolving tip-based machining. Nanomanuf Metrol 2:26-35. https:// doi.org/10.1007/s41871-018-0032-9

47. Jaouen K, Henrotte O, Campidelli S, Jousselme B, Derycke V, Cornut R (2017) Localized electrochemistry for the investigation and the modification of 2D materials. Appl Mater Today 8:116-124. https://doi.org/10.1016/j.apmt.2017.05.001

48. Yamamoto K, Sato K, Sasano J, Nagai M, Shibata T (2017) Localized etching of silicon in water using a catalytically active platinum-coated atomic force microscopy probe. Precis Eng 50:344-353. https://doi.org/10.1016/j.precisioneng.2017.06.008

49. Hu H, Kim H, Somnath S (2017) Tip-based nanofabrication for scalable manufacturing. Micromachines 8:90. https://doi. org/10.3390/mi8030090

50. Jiang Y, Guo W (2008) Convex and concave nanodots and lines induced on HOPG surfaces by AFM voltages in ambient air. Nanotechnology 19:345302. https://doi.org/10.1088/09574484/19/34/345302

51. Choi CH, Lee DJ, Sung J-H, Lee MW, Lee S-G, Park S-G et al (2010) A study of AFM-based scratch process on polycarbonate surface and grating application. Appl Surf Sci 256:7668-7671. https://doi.org/10.1016/j.apsusc.2010.06.025

52. Sugihara H, Takahara A, Kajiyama T (2001) Mechanical nanofabrication of lignoceric acid monolayer with atomic force microscopy. J Vac Sci Technol B 19:593. https://doi. org/10.1116/1.1347042

53. Zhang Y, Balaur E, Schmuki P (2006) Nanopatterning of an organic monolayer covered $\mathrm{Si}$ (111) surfaces by atomic force microscope scratching. Electrochim Acta 51:3674-3679. https ://doi.org/10.1016/j.electacta.2005.10.030

54. Zhu P, Fang FZ (2014) On the mechanism of material removal in nanometric cutting of metallic glass. Appl Phys A 116:605-610. https://doi.org/10.1007/s00339-013-8189-y

55. Tseng AA (2011) Tip-based nanofabrication: fundamentals and applications. Springer, Berlin

56. Tseng AA (2011) Removing material using atomic force microscopy with single- and multiple-tip sources. Small 7:3409-3427. https://doi.org/10.1002/smll.201100486

57. Fang FZ, Xu F (2018) Recent advances in micro/nano-cutting: effect of tool edge and material properties. Nanomanuf Metrol 1:4-31. https://doi.org/10.1007/s41871-018-0005-Z

58. Yan Y, Geng Y, Hu Z (2015) Recent advances in AFM tip-based nanomechanical machining. Int J Mach Tool Manuf 99:1-18. https://doi.org/10.1016/j.ijmachtools.2015.09.004

59. Samsonov GV (1968) Mechanical properties of the elements. In: Samsonov GV (ed) Handbook of the physicochemical properties of the elements. Springer, Boston, pp 387-446. https://doi. org/10.1007/978-1-4684-6066-7_7

60. Sumigawa T, Ashida S, Tanaka S, Sanada K, Kitamura T (2015) Fracture toughness of silicon in nanometer-scale singular stress field. Eng Fract Mech 150:161-167. https://doi.org/10.1016/j. engfracmech.2015.05.054
61. Zhang P, Ma L, Fan F, Zeng Z, Peng C, Loya PE et al (2014) Fracture toughness of graphene. Nat. Commun. 5:3782. https:// doi.org/10.1038/ncomms4782

62. Cutnell JD, Johnson KW (1998) Physics, 4th edn. Wiley, New York

63. Efunda (2020) Mohs hardness scale. https://www.efunda.com/ units/hardness/convert_hardness.cfm?cat $=$ Steel $\& \mathrm{HD}=\mathrm{HM}$. Accessed 13 April 2020

64. Preiß EI, Merle B, Göken M (2017) Understanding the extremely low fracture toughness of freestanding gold thin films by in situ bulge testing in an AFM. Mater Sci Eng A 691:218-225. https ://doi.org/10.1016/j.msea.2017.03.037

65. Accuratus (2013) Silicon Carbide Material Properties. https:// accuratus.com/pdf/sicprops.pdf. Accessed 13 April 2020

66. AZoM (2001) Silicon Carbide (SiC) Properties and Applications. https://www.azom.com/properties.aspx?ArticleID=42. Accessed 13 April 2020

67. Gómez-Moñivas S, Sáenz JJ, Calleja M, García R (2003) FieldInduced Formation of Nanometer-Sized Water Bridges. Phys Rev Lett 91:056101. https://doi.org/10.1103/PhysRevLett.91.056101

68. Dagata JA, Schneir J, Harary HH, Evans CJ, Postek MT, Bennett J (1990) Modification of hydrogen-passivated silicon by a scanning tunneling microscope operating in air. Appl Phys Lett 56:2001-2003. https://doi.org/10.1063/1.102999

69. Snow ES, Campbell PM (1995) AFM fabrication of Sub-10-nanometer metal-oxide devices with in situ control of electrical properties. Science 270:1639-1641. https://doi.org/10.1126/scien ce. 270.5242 .1639

70. Chien FSS, Chang J-W, Lin S-W, Chou Y-C, Chen TT, Gwo S et al (2000) Nanometer-scale conversion of Si3N4 to SiOx. Appl Phys Lett 76:360-362. https://doi.org/10.1063/1.125754

71. Kuramochi H, Ando K, Tokizaki T, Yokoyama H (2004) In situ detection of faradaic current in probe oxidation using a dynamic force microscope. Appl Phys Lett 84:4005-4007. https://doi. org/10.1063/1.1748842

72. Avouris P, Hertel T, Martel R (1997) Atomic force microscope tip-induced local oxidation of silicon: kinetics, mechanism, and nanofabrication. Appl Phys Lett 71:285-287. https://doi. org/10.1063/1.119521

73. Snow ES, Jernigan GG, Campbell PM (2000) The kinetics and mechanism of scanned probe oxidation of Si. Appl Phys Lett 76:1782-1784. https://doi.org/10.1063/1.126166

74. Dagata JA, Perez-Murano F, Abadal G, Morimoto K, Inoue $\mathrm{T}$, Itoh J et al (2000) Predictive model for scanned probe oxidation kinetics. Appl Phys Lett 76:2710-2712. https://doi. org/10.1063/1.126451

75. Dubois E, Bubendorff JL (2000) Kinetics of scanned probe oxidation: space-charge limited growth. J Appl Phys 87:8148-8154. https://doi.org/10.1063/1.373510

76. Jiao N, Wang Y, Xi N, Dong Z (2008) Electric field assisted fabrication on Si and HOPG surfaces by AFM. In: 2nd IEEE international nanoelectronics conference, Shanghai, China. IEEE. pp 1155-1158. https://doi.org/10.1109/INEC.2008.4585687

77. Freund J, Halbritter J, Hörber JKH (1999) How dry are dried samples? Water adsorption measured by STM. Microsc Res Tech 44:327. https://doi.org/10.1002/(SICI)1097-0029(19990 301)44:5\%3c327:AID-JEMT3\%3e3.0.CO;2-E

78. Ahn JJ, Jo Y-D, Kim S-C, Lee J-H, Koo S-M (2011) Crystallographic plane-orientation dependent atomic force microscopybased local oxidation of silicon carbide. Nanoscale Res Lett 6:235. https://doi.org/10.1186/1556-276X-6-235

79. Lorenzoni M, Torre B (2013) Scanning probe oxidation of SiC, fabrication possibilities and kinetics considerations. Appl Phys Lett 103:163109. https://doi.org/10.1063/1.4825265 
80. Petersen KE (1982) Silicon as a mechanical material. Proc IEEE 70:420-457. https://doi.org/10.1109/PROC.1982.12331

81. Calleja M, Anguita J, Garcia R, Birkelund K, Pérez-Murano F, Dagata JA (1999) Nanometre-scale oxidation of silicon surfaces by dynamic force microscopy: reproducibility, kinetics and nanofabrication. Nanotechnology 10:34-38. https://doi. org/10.1088/0957-4484/10/1/008

82. Snow ES, Campbell PM (1994) Fabrication of Si nanostructures with an atomic force microscope. Appl Phys Lett 64:1932-1934. https://doi.org/10.1063/1.111746

83. Snow ES, Juan WH, Pang SW, Campbell PM (1995) Si nanostructures fabricated by anodic oxidation with an atomic force microscope and etching with an electron cyclotron resonance source. Appl Phys Lett 66:1729-1731. https://doi. org/10.1063/1.113348

84. Avouris P, Martel R, Hertel T, Sandstrom R (1998) AFMtip-induced and current-induced local oxidation of silicon and metals. Appl Phys A Mater 66:S659-S667. https://doi. org/10.1007/s003390051218

85. Chien FSS, Chou YC, Chen TT, Hsieh W-F, Chao T-S, Gwo S (2001) Nano-oxidation of silicon nitride films with an atomic force microscope: chemical mapping, kinetics, and applications. J Appl Phys 89:2465-2472. https://doi. org/10.1063/1.1339212

86. Jiang X, Wu G, Zhou J, Wang S, Tseng AA, Du Z (2011) Nanopatterning on silicon surface using atomic force microscopy with diamond-like carbon (DLC)-coated Si probe. Nanoscale Res Lett 6:518. https://doi.org/10.1186/1556-276X-6-518

87. Mathew PT, Fang FZ (2018) Advances in molecular electronics: a brief review. Engineering 4:760-771. https://doi.org/10.1016/j. eng.2018.11.001

88. Fang FZ, Liu B, Xu Z (2015) Nanometric cutting in a scanning electron microscope. Precis Eng 41:145-152. https://doi. org/10.1016/j.precisioneng.2015.01.009

89. Seidel H (1990) Anisotropic etching of crystalline silicon in alkaline solutions. J Electrochem Soc 137:3612. https://doi. org/10.1149/1.2086277

90. Elwenspoek M, Jansen HV (1998) Silicon micromachining. Cambridge University Press, Cambridge, New York

91. Mo Y, Zhao W, Huang D, Zhao F, Bai M (2009) Nanotribological properties of precision-controlled regular nanotexture on $\mathrm{H}$-passivated $\mathrm{Si}$ surface by current-induced local anodic oxidation. Ultramicroscopy 109:247-252. https://doi.org/10.1016/j. ultramic.2008.10.025

92. Al-Musawi RSJ, Brousseau EB, Geng Y, Borodich FM (2016) Insight into mechanics of AFM tip-based nanomachining: bending of cantilevers and machined grooves. Nanotechnology 27:385302. https://doi.org/10.1088/0957-4484/27/38/385302

93. Kim US, Morita N, Lee DW, Jun M, Park JW (2017) The possibility of multi-layer nanofabrication via atomic force microscope-based pulse electrochemical nanopatterning. Nanotechnology 28:195302. https://doi.org/10.1088/1361-6528/aa6954

94. Goel S, Luo X, Agrawal A, Reuben RL (2015) Diamond machining of silicon: a review of advances in molecular dynamics simulation. Int J Mach Tool Manuf 88:131-164. https://doi. org/10.1016/j.ijmachtools.2014.09.013

95. Khurshudov A, Kato K (1995) Wear of the atomic force microscope tip under light load, studied by atomic force microscopy. Ultramicroscopy 60:11-16. https://doi.org/10.1016/03043991(95)00071-8

96. Bloo ML, Haitjema H, Pril WO (1999) Deformation and wear of pyramidal, silicon-nitride AFM tips scanning micrometre-size features in contact mode. Measurement 25:203-211. https://doi. org/10.1016/S0263-2241(99)00004-4

97. Fletcher PC, Felts JR, Dai Z, Jacobs TD, Zeng H, Lee W et al (2010) Wear-resistant diamond nanoprobe tips with integrated silicon heater for tip-based nanomanufacturing. ACS Nano 4:3338-3344. https://doi.org/10.1021/nn100203d

98. Liu J, Notbohm JK, Carpick RW, Turner KT (2010) Method for characterizing nanoscale wear of atomic force microscope tips. ACS Nano 4:3763-3772. https://doi.org/10.1021/nn100246g

99. Bhaskaran H, Sebastian A, Drechsler U, Despont M (2009) Encapsulated tips for reliable nanoscale conduction in scanning probe technologies. Nanotechnology 20:105701. https://doi. org/10.1088/0957-4484/20/10/105701

100. Bhaskaran H, Sebastian A, Despont M (2009) Nanoscale PtSi tips for conducting probe technologies. IEEE Trans Nanotechnol 8:128-131. https://doi.org/10.1109/TNANO.2008.2005199

101. Givargizov EI, Zhiraov VV, Kuznetsov AV, Plekhanov PS (1993) Growth of diamond particles on sharpened silicon tips. Mater Lett 18:61-63. https://doi.org/10.1016/0167-577X(93)90057-5

102. Tanasa G, Kurnosikov O, Flipse CFJ, Buijnsters JG, van Enckevort WJP (2003) Diamond deposition on modified silicon substrates: making diamond atomic force microscopy tips for nanofriction experiments. J Appl Phys 94:1699-1704. https:// doi.org/10.1063/1.1590058

103. Kim KH, Moldovan N, Ke C, Espinosa HD, Xiao X, Carlisle JA et al (2005) Novel ultrananocrystalline diamond probes for high-resolution low-wear nanolithographic techniques. Small 1:866-874. https://doi.org/10.1002/smll.200500028

104. Bhaskaran H, Gotsmann B, Sebastian A, Drechsler U, Lantz MA, Despont $M$ et al (2010) Ultralow nanoscale wear through atomby-atom attrition in silicon-containing diamond-like carbon. Nat Nanotechnol 5:181-185. https://doi.org/10.1038/nnano.2010.3

105. Jeng YR, Islam S, Wu K-T, Erdemir A, Eryilmaz O (2017) Investigation of nano-mechanical and- tribological properties of hydrogenated diamond like carbon (DLC) coatings. J Mech 33:769-776. https://doi.org/10.1017/jmech.2016.106

106. Promyoo R, El-Mounayri H, Agarwal M, Karingula VK, Varahramyan K (2016) Tip-based nanomanufacturing of nanofluidics using atomic force microscopy. J. Micro. NanoManuf. 4:041003. https://doi.org/10.1115/1.4034608

107. Cheng GJ (2005) Design and fabrication of a hybrid nanofluidic channel. J. Micro-Nanolith MEM 4:013009. https://doi. org/10.1117/1.1869132

108. Mathew PT, Fang FZ (2020) Periodic energy decomposition analysis for electronic transport studies as a tool for atomic scale manufacturing. Int J Extrem Manuf 2:015401. https://doi. org/10.1088/2631-7990/ab5d8a

109. Huang J-C, Chen C-M (2012) High-voltage nano-oxidation in deionized water and atmospheric environments by atomic force microscopy: high-voltage nano-oxidation in DI water and atmospheric environments by AFM. Scanning. 34:230-236. https://doi. org/10.1002/sca.20298

110. Dehzangi A, Larki F, Hutagalung SD, Goodarz Naseri M, Majlis BY, Navasery M et al (2013) Impact of parameter variation in fabrication of nanostructure by atomic force microscopy nanolithography. PLoS ONE 8:e65409. https://doi.org/10.1371/journ al.pone.0065409

111. Geng Y, Yan Y, Wang J, Zhuang Y (2018) Fabrication of nanopatterns on silicon surface by combining AFM-based scratching and RIE Methods. Nanomanuf Metrol 1:225-235. https://doi. org/10.1007/s41871-018-0024-9

112. Dong Z, Wejinya UC (2012) Atomic Force Microscopy-based repeatable surface nanomachining for nanochannels on bare silicon substrates. In: 12th IEEE international conference on nanotechnology (IEEE-NANO), Birmingham, UK: IEEE, pp 1-5. https://doi.org/10.1109/NANO.2012.6321911

113. Temiryazev A (2014) Pulse force nanolithography on hard surfaces using atomic force microscopy with a sharp singlecrystal diamond tip. Diam Relat Mater 48:60-64. https://doi. org/10.1016/j.diamond.2014.07.001 
114. Tello M, García R (2001) Nano-oxidation of silicon surfaces: comparison of noncontact and contact atomic-force microscopy methods. Appl Phys Lett 79:424-426. https://doi. org/10.1063/1.1385582

115. Schuster R (2000) Electrochemical micromachining. Science 289:98-101. https://doi.org/10.1126/science.289.5476.98

116. Lee JM, Kim YB, Park JW (2013) Pulse electrochemical $\mathrm{meso} / \mathrm{micro} /$ nano ultraprecision machining technology. J Nanosci Nanotechnol 13:7741-7744. https://doi.org/10.1166/ jnn.2013.7716

117. Zhang J, Sartin MM, Guo J, Chen D, Lai J, Han L et al (2019) tip-substrate distance-dependent etching process of III-V semiconductors investigated by scanning electrochemical microscopy. J Phys Chem C 123:25712-25718. https://doi.org/10.1021/acs. jpcc.9b07335

118. Ki B, Choi K, Kim K, Oh J (2020) Electrochemical local etching of silicon in etchant vapor. Nanoscale 12:6411-6419. https://doi. org/10.1039/C9NR10420H

119. Kawasegi N, Takano N, Oka D, Morita N, Yamada S, Kanda K et al (2006) Nanomachining of silicon surface using atomic force microscope with diamond tip. J Manuf Sci Eng 128:723-729. https://doi.org/10.1115/1.2163364

120. Lee SH (2012) Analysis of ductile mode and brittle transition of AFM nanomachining of silicon. Int J Mach Tool Manuf 61:7179. https://doi.org/10.1016/j.ijmachtools.2012.05.011

121. Wang J, Fang FZ, Yan G, Guo Y (2019) Study on diamond cutting of ion implanted tungsten carbide with and without ultrasonic vibration. Nanomanuf Metrol 2:177-185. https://doi. org/10.1007/s41871-019-00042-6

122. Iye $Y$ (2011) Electronic states and transport properties of carbon crystalline: graphene, nanotube, and graphite. In: Battacharya P, Fornari R, Kamimura H (eds) Comprehensive semiconductor science and technology. Elsevier, Amsterdam, pp 359-382. https ://doi.org/10.1016/B978-0-44-453153-7.00068-7

123. Roy HV, Kallinger C, Marsen B, Sattler K (1998) Manipulation of graphitic sheets using a tunneling microscope. J Appl Phys 83:4695-4699. https://doi.org/10.1063/1.367257

124. Sidorov AN, Yazdanpanah MM, Jalilian R, Ouseph PJ, Cohn RW, Sumanasekera GU (2007) Electrostatic deposition of graphene. Nanotechnology 18:135301. https://doi.org/10.1088/0957$4484 / 18 / 13 / 135301$

125. Novoselov KS (2004) Electric field effect in atomically thin carbon films. Science 306:666-669. https://doi.org/10.1126/scien ce. 1102896

126. Malik R, Tomer VK, Chaudhary V (2019) Hybridized graphene for chemical sensing. In: Jawaid M, Bouhfid R, Qaiss AK (eds) Functionalized graphene nanocomposites and their derivatives. Elsevier, Amsterdam, pp 323-338. https://doi.org/10.1016/B9780-12-814548-7.00016-7

127. Lu X, Yu M, Huang H, Ruoff RS (1999) Tailoring graphite with the goal of achieving single sheets. Nanotechnology 10:269-272. https://doi.org/10.1088/0957-4484/10/3/308

128. Chung DDL (2001) Graphite intercalation compounds. In: Buschow KHJ, Cahn RW, Veyssiere P (eds) Encyclopedia of materials: science and technology, 2nd edn. Elsevier, Amsterdam, pp 3641-3645. https://doi.org/10.1016/B0-08-04315 2-6/00649-5

129. Miyake S, Wang M (2015) Nanoprocessing of layered crystalline materials by atomic force microscopy. Nanoscale Res Lett 10:123. https://doi.org/10.1186/s11671-015-0811-9

130. Hassani SS, Sobat Z, Aghabozorg HR (2010) Force nanolithography on various surfaces by atomic force microscope. IJNM 5:217. https://doi.org/10.1504/IJNM.2010.033863

131. Yang $Y$, Lin $J$ (2016) Investigation of the transition from local anodic oxidation to electrical breakdown during nanoscale atomic force microscopy electric lithography of highly oriented pyrolytic graphite. Microsc Microanal 22:432-439. https://doi. org/10.1017/S1431927616000027

132. Park JG, Zhang C, Liang R, Wang B (2007) Nano-machining of highly oriented pyrolytic graphite using conductive atomic force microscope tips and carbon nanotubes. Nanotechnology 18:405306. https://doi.org/10.1088/0957-4484/18/40/405306

133. Gowthami T, Gadhewal M, Raina G (2013) Study of stability of local anodic oxidation on HOPG and few layer graphene using AFM in ambient. IEEE Trans Nanotechnol 12:1002-1006. https ://doi.org/10.1109/TNANO.2013.2274900

134. Kurra N, Prakash G, Basavaraja S, Fisher TS, Kulkarni GU, Reifenberger RG (2011) Charge storage in mesoscopic graphitic islands fabricated using AFM bias lithography. Nanotechnology 22:245302. https://doi.org/10.1088/0957-4484/22/24/245302

135. Qi Y, Liu J, Zhang J, Dong Y, Li Q (2017) Wear resistance limited by step edge failure: the rise and fall of graphene as an atomically thin lubricating material. ACS Appl Mater Interfaces 9:1099-1106. https://doi.org/10.1021/acsami.6b12916

136. Shokrieh MM, Hosseinkhani MR, Naimi-Jamal MR, Tourani H (2013) Nanoindentation and nanoscratch investigations on graphene-based nanocomposites. Polym Testing 32:45-51. https:// doi.org/10.1016/j.polymertesting.2012.09.001

137. Zhan B, Li C, Yang J, Jenkins G, Huang W, Dong X (2014) Graphene field-effect transistor and its application for electronic sensing. Small 2014:1-24. https://doi.org/10.1002/smll.20140 0463

138. Xin T, King WCL (2014) Quantitative study of AFM-based nanopatterning of graphene nanoplate. In: 14th IEEE international conference on nanotechnology, Toronto, ON, Canada. https://doi. org/10.1109/NANO.2014.6968106

139. Mathew PT, Fang FZ, Nadal LV, Cronin L, Georgiev V (2019) First principle simulations of current flow in inorganic molecules: polyoxometalates (POMs). IEEExplore, Grenoble, France. https://doi.org/10.1109/EUROSOI-ULIS45800.2019.9041869

140. Heath JR, Ratner MA (2003) Molecular electronics. Phys Today 56:43-49. https://doi.org/10.1063/1.1583533

141. Famili M, Jia C, Liu X, Wang P, Grace IM, Guo J et al (2019) Self-assembled molecular-electronic films controlled by room temperature quantum interference. Chemistry 5:474-484. https ://doi.org/10.1016/j.chempr.2018.12.008

142. Osorio HM, Cea P, Ballesteros LM, Gascón I, Marqués-González S, Nichols RJ et al (2014) Preparation of nascent molecular electronic devices from gold nanoparticles and terminal alkyne functionalised monolayer films. J Mater Chem C 2:7348-7355. https ://doi.org/10.1039/C4TC01080A

143. Bian B, Yang J, Han X, Wei J (2019) Electronic transport induced by asymmetric adsorption site of sulfur in molecular device. Surf Sci 684:52-57. https://doi.org/10.1016/j.susc.2019.02.006

144. Venkataraman A, Zhang P, Papadopoulos C (2019) Electronic transport in metal-molecular nanoelectronic networks: a density functional theory study. AIP Adv 9:035122. https://doi. org/10.1063/1.5087413

145. Kondo T, Morita J, Hanaoka K, Takakusagi S, Tamura K, Takahasi $M$ et al (2007) Structure of $\mathrm{Au}(111)$ and $\mathrm{Au}(100)$ Singlecrystal electrode surfaces at various potentials in sulfuric acid solution determined by in situ surface $\mathrm{x}$-ray scattering. J Phys Chem C 111:13197-13204. https://doi.org/10.1021/jp072601j

146. Sumomogi $T$ (1994) Micromachining of metal surfaces by scanning probe microscope. J Vac Sci Technol B 12:1876. https://doi. org/10.1116/1.587660

147. Watanabe M, Minoda H, Takayanagi K (2004) Fabrication of gold nanowires using contact mode atomic force microscope. Jpn J Appl Phys 43:6347-6349. https://doi.org/10.1143/JJAP.43.6347

148. Zhang HY (2013) Nano structures constructed by AFM based lithography. AMR 815:490-495. https://doi.org/10.4028/www. scientific.net/AMR.815.490 
149. Li X, Nardi P, Baek C-W, Kim J-M, Kim YK (2005) Direct nanomechanical machining of gold nanowires using a nanoindenter and an atomic force microscope. J Micromech Microeng 15:551-556. https://doi.org/10.1088/0960-1317/15/3/016

150. Fang TH, Chang W-J, Weng C-I (2006) Nanoindentation and nanomachining characteristics of gold and platinum thin films. Mater Sci Eng A 430:332-340. https://doi.org/10.1016/j. msea.2006.05.106

151. Shao J, Josephs EA, Lee C, Lopez A, Ye T (2013) Electrochemical etching of gold within nanoshaved self-assembled monolayers. ACS Nano 7:5421-5429. https://doi.org/10.1021/nn4014005

152. Chaussende D, Ohtani N (2019) Silicon carbide. In: Fornari R (ed) Single crystals of electronic materials. Elsevier, Amsterdam, pp 129-179. https://doi.org/10.1016/B978-0-08-102096-8.00005-7

153. Smith TP, Davis RF (2011) Silicon carbide. In: Buschow KHJ, Cahn RW, Veyssiere P (eds) Encyclopedia of materials: science and technology, 2nd edn. Elsevier, Amsterdam, pp 1-6. https:// doi.org/10.1016/B0-08-043152-6/01518-7

154. Rowe WB (2009) Grinding wheel developments. In: Rowe WB (ed) Principles of modern grinding technology. Elsevier, Amsterdam, pp 35-58. https://doi.org/10.1016/B978-0-81552018-4.50009-4

155. Li J, Filip O, Epelbaum BM, Xu X, Bickermann M, Winnacker A (2007) Growth of $4 \mathrm{H}-\mathrm{SiC}$ on rhombohedral (0114) plane seeds. J Cryst Growth 308:41-49. https://doi.org/10.1016/j.jcrys gro.2007.07.039

156. Xie XN, Chung HJ, Sow CH, Wee ATS (2004) Native oxide decomposition and local oxidation of $6 \mathrm{H}-\mathrm{SiC}(0001)$ surface by atomic force microscopy. Appl Phys Lett 84:4914-4916. https:// doi.org/10.1063/1.1728305

157. Giocondi J, Rohrer GS, Skowronski M, Balakrishna V, Augustine G, Hobgood HM et al (1997) An atomic force microscopy study of super-dislocation/micropipe complexes on the $6 \mathrm{H}-\mathrm{SiC}(0001)$ growth surface. J Cryst Growth 181:351-362. https://doi. org/10.1016/S0022-0248(97)00303-5

158. Han JH, Yoon D-Y (2010) 3D CFD for chemical transport profiles in a rotating disk CVD reactor. 3D Res 1:5. https://doi. org/10.1007/3DRes.02(2010)05

159. Yin L, Vancoille EYJ, Ramesh K, Huang H (2004) Surface characterization of $6 \mathrm{H}-\mathrm{SiC}(0001)$ substrates in indentation and abrasive machining. Int J Mach Tool Manuf 44:607-615. https ://doi.org/10.1016/j.ijmachtools.2003.12.006

160. Watanabe J, Fujimoto M, Matsumoto Y, Kuroda N, Eryu O (2003) Evaluation of surfaces of single SiC crystal polished with various kinds of particles. KEM 238-239:175-182. https://doi. org/10.4028/www.scientific.net/KEM.238-239.175

161. Tanaka H, Shimada S (2013) Damage-free machining of monocrystalline silicon carbide. CIRP Ann 62:55-58. https:// doi.org/10.1016/j.cirp.2013.03.098

162. Zhang F, Meng B, Geng Y, Zhang Y (2016) Study on the machined depth when nanoscratching on $6 \mathrm{H}-\mathrm{SiC}$ using Berkovich indenter: modelling and experimental study. Appl Surf Sci 368:449-455. https://doi.org/10.1016/j.apsusc.2016.02.032

163. Meng B, Yuan D, Zheng J, Qiu P, Xu S (2020) Tip-based nanomanufacturing process of single crystal SiC: ductile deformation mechanism and process optimization. Appl Surf Sci 500:144039. https://doi.org/10.1016/j.apsusc.2019.144039

164. Fang FZ (2016) Atomic and close-to-atomic scale manufacturing - a trend in manufacturing development. Front Mech Eng 11:325-327. https://doi.org/10.1007/s11465-016-0402-1

165. Fang FZ (2015) "Manufacturing III" is the strategic choice for manufacturing development. People's Forum 2(16):59-61

166. Xie W, Fang FZ (2019) Cutting-based single atomic layer removal mechanism of monocrystalline copper: edge radius effect. Nanoscale Res Lett 14:370. https://doi.org/10.1186/s1167 1-019-3195-4
167. Xie W, Fang FZ (2019) Cutting-based single atomic layer removal mechanism of monocrystalline copper: atomic sizing effect. Nanomanuf Metrol 2:241-252. https://doi.org/10.1007/ s41871-019-00045-3

168. Xie W, Fang FZ (2020) Effect of tool edge radius on material removal mechanism in atomic and close-to-atomic scale cutting. Appl Surf Sci 504:144451. https://doi.org/10.1016/j.apsus c.2019.144451

169. Xie W, Fang FZ (2019) Mechanism of atomic and close-toatomic scale cutting of monocrystalline copper. Appl Surf Sci 503:144239. https://doi.org/10.1016/j.apsusc.2019.144239

170. Ren J, Zhao J, Dong Z, Liu P (2015) Molecular dynamics study on the mechanism of AFM-based nanoscratching process with water-layer lubrication. Appl Surf Sci 346:84-98. https://doi. org/10.1016/j.apsusc.2015.03.177

171. Otto MR, René de Cotret LP, Valverde-Chavez DA, Tiwari KL, Émond N, Chaker M et al (2019) How optical excitation controls the structure and properties of vanadium dioxide. Proc Natl Acad Sci 116:450-455. https://doi.org/10.1073/pnas.1808414115

172. Zhu P, Fang FZ (2016) Study of the minimum depth of material removal in nanoscale mechanical machining of single crystalline copper. Comput Mater 118:192-202. https://doi.org/10.1016/j. commatsci.2016.03.023

173. Vettiger P, Despont M, Drechsler U, Durig U, Haberle W, Lutwyche MI et al (2000) The "Millipede"-more than thousand tips for future AFM storage. IBM J Res Dev 44:323-340. https ://doi.org/10.1147/rd.443.0323

174. Fang FZ, Gu C, Hao R, You K, Huang S (2018) Recent progress in surface integrity research and development. Engineering 4:754-758. https://doi.org/10.1016/j.eng.2018.11.005

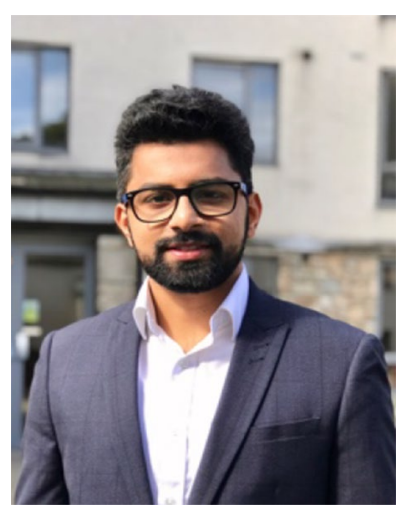

Mr. Paven Thomas Mathew received his B.Sc. Degree in Physics from Christian College Chengannur (India) in 2015 and M.Sc. Degree in Physics from Madras Christian College (India) in 2017. He joined MNMT-Dublin, University College Dublin, Ireland in 2018 to pursue his $\mathrm{Ph}$.D. under the supervision of Prof. Fengzhou Fang. His research focus is in developing fundamental aspects and perspectives of ACSM.

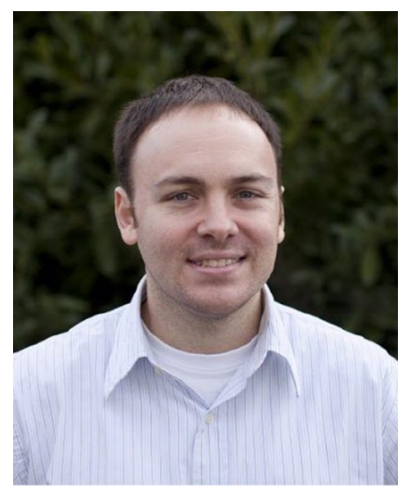

Brian J. Rodriguez completed his Ph.D. in Physics at North Carolina State University in 2003 and subsequently held postdoctoral appointments at North Carolina State University and at Oak Ridge National Laboratory. In 2007, he received an Alexander von Humboldt fellowship and carried out his research at the Max Planck Institute of Microstructure Physics in Halle, Germany. He joined UCD in 2009 and his primary research interests span many aspects of scanning probe microscopy. 


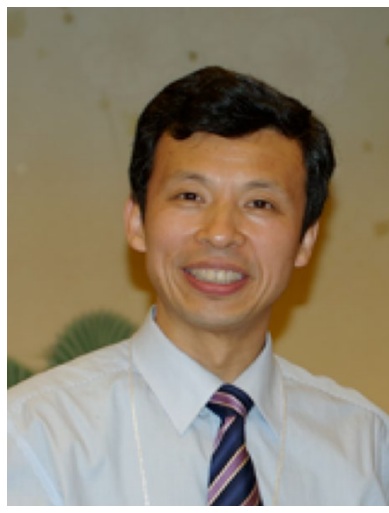

ISNM, AET, CIRP, and SME.
Fengzhou Fang is a joint Professor and the director of Centre of Micro/Nano Manufacturing Technology (MNMT) at Tianjin University and University College Dublin. He has been doing both fundamental studies and application development in the areas of optical freeform design and manufacturing, visual optics and bio-implants manufacturing, ACSM, ultra-precision machining and measurement benefiting a variety of industries in medical devices, bio-implants, optics and mold sectors. He is a Fellow of 